\title{
Nox4 and redox signaling mediate TGF- $\beta$-induced endothelial cell apoptosis and phenotypic switch
}

\author{
F Yan ${ }^{1}$, Y Wang ${ }^{1}, X$ Wu ${ }^{1}$, HM Peshavariya ${ }^{2}$, GJ Dusting ${ }^{2}$, M Zhang ${ }^{1}$ and F Jiang ${ }^{*, 1}$
}

Transforming growth factor- $\beta$ (TGF- $\beta$ ) triggers apoptosis in endothelial cells, while the mechanisms underlying this action are not entirely understood. Using genetic and pharmacological tools, we demonstrated that TGF- $\beta$ induced a moderate apoptotic response in human cultured endothelial cells, which was dependent upon upregulation of the Nox4 NADPH oxidase and production of reactive oxygen species (ROS). In contrast, we showed that ectopic expression of Nox4 via viral vectors (vNox4) produced an antiapoptotic effect. TGF- $\beta$ caused ROS-dependent p38 activation, whereas inhibition of p38 blunted TGF- $\beta$ induced apoptosis. However, vNox4, but not TGF- $\beta$, activated Akt, and inhibition of Akt attenuated the antiapoptotic effect of vNox4. Akt activation induced by vNox4 was accompanied by inactivation of the protein tyrosine phosphatase-1B (PTP1B) function and enhanced vascular endothelial growth factor receptor (VEGFR)-2 phosphorylation. Moreover, we showed that TGF- $\beta$ enhanced Notch signaling and increased expression of the arterial marker EphrinB2 in a redox-dependent manner. In summary, our results suggest that Nox4 and ROS have pivotal roles in mediating TGF- $\beta$-induced endothelial apoptosis and phenotype specification. Redox mechanisms may influence endothelial cell functions by modulating p38, PTP1B/VEGFR/Akt and Notch signaling pathways.

Cell Death and Disease (2014) 5, e1010; doi:10.1038/cddis.2013.551; published online 23 January 2014

Subject Category: Experimental Medicine

Transforming growth factor- $\beta$ (TGF- $\beta$ ) has pleiotropic effects in regulating cardiovascular physiology and disease, whereas one of the major targets of TGF- $\beta$ in the vasculature is endothelial cells. ${ }^{1,2}$ Disruption of TGF- $\beta$ signaling in endothelial cells results in impaired vascular development in the embryo, ${ }^{1}$ and TGF- $\beta$ also has pivotal roles in postnatal angiogenesis. ${ }^{3}$ In addition, TGF- $\beta$ has been implicated in modulating endothelial cell proliferation, apoptosis, permeability and morphogenesis. ${ }^{4-7}$ There is evidence that TGF- $\beta$ concentration in the plasma is elevated in patients with risk factors of cardiovascular disease, including obesity and diabetes. ${ }^{8,9}$ Moreover, an increased level of circulating TGF- $\beta$ was found in women with preeclampsia. ${ }^{10}$ In atherosclerosisprone apolipoprotein (E)-deficient mice, systemic elevation of TGF- $\beta$ expression induced endothelial oxidative stress and dysfunction. ${ }^{11}$ Remarkably, the biological effects of TGF- $\beta$ in endothelial cells are often dichotomous (either protective or detrimental), depending on the cellular context and the type of endothelial cells involved. ${ }^{4,7,12,13}$

In endothelial cells, TGF- $\beta$-induced effects are mainly mediated by the membrane receptors activin receptor-like kinase 1 (ALK1) and ALK5. Stimulation of the ALK1 receptor phosphorylates Smad1/5/8, whereas stimulation of ALK5 triggers phosphorylation of Smad2/3. These activated Smad proteins then work together with Smad4 as a transcriptional activating complex to regulate the expression of various target genes, ${ }^{1,3}$ whereas activation of ALK1 and ALK5 may induce distinct cellular effects in endothelium. ${ }^{14}$ In addition to these canonical signaling pathways, emerging evidence suggests that NADPH oxidase-dependent redox mechanisms may also be involved in mediating the biological actions of TGF- $\beta$. In particular, TGF- $\beta$ specifically upregulates expression of the Nox4 type of NADPH oxidase in a variety of cells (including vascular cells). ${ }^{15-19}$ More importantly, these studies have demonstrated that blockade of Nox4 expression or function inhibits TGF- $\beta$-induced effects on multiple cell functions, indicating a pivotal role of Nox4 in TGF- $\beta$ signaling.

Several lines of evidence have shown that TGF- $\beta$ can trigger an apoptotic response in different types of endothelial cells. $^{7,20,21}$ However, the signaling mechanisms underlying this action of TGF- $\beta$ are poorly understood. Lu et al. ${ }^{7}$ demonstrated that TGF- $\beta$-induced apoptosis in pulmonary microvascular endothelial cells was dependent on the ALK5Smad2 pathway and subsequent downregulation of the antiapoptotic genes Bcl-2 and cFLIP. On the other hand, several studies have pointed to a critical role of activation of the

\footnotetext{
${ }^{1}$ Key Laboratory of Cardiovascular Remodeling and Function Research, Qilu Hospital, Shandong University, Jinan, Shandong Province, China and ${ }^{2}$ Centre for Eye Research Australia, University of Melbourne, East Melbourne, Victoria, Australia

*Corresponding author: F Jiang, Key Laboratory of Cardiovascular Remodeling and Function Research, Qilu Hospital, 107 Wen Hua Xi Road, Jinan, Shandong Province 250012, China. Tel: +86 5318216 9267; Fax: +86 5318616 9356; E-mail: fjiang@ sdu.edu.cn

Keywords: transforming growth factor- $\beta$; apoptosis; endothelial cell; Nox4; p38; arterial-venous specification

Abbreviations: ALK, activin receptor-like kinase; ANOVA, analysis of variance; DCFH-DA, 2', $7^{\prime}$-dichlorofluorescin diacetate; DTT, dithiothreitol; ECM, endothelial cell medium; HMVEC, human dermal microvascular endothelial cell; HUVEC, human umbilical vein endothelial cell; MAPK, mitogen-activated protein kinase; NAC, N-acetylL-cysteine; NICD, Notch intracellular domain; PTP1B, protein tyrosine phosphatase-1B; qPCR, quantitative real-time PCR; ROS, reactive oxygen species; shRNA, short hairpin RNA; TGF- $\beta$, transforming growth factor- $\beta$; TUNEL, terminal deoxynucleotidyl transferase-mediated dUTP nick end labeling; VEGF, vascular endothelial growth factor; VEGFR, VEGF receptor; vNox4, lentiviral vector expressing Nox4; $\Delta \Psi \mathrm{m}$, mitochondrial membrane potential

Received 09.9.13; revised 08.12.13; accepted 13.12.13; Edited by M Agostini
} 
p38 mitogen-activated protein kinase (MAPK) in mediating TGF- $\beta$-induced endothelial apoptosis. ${ }^{21,22}$ Nevertheless, so far there is little information about whether TGF- $\beta$-induced apoptosis in endothelial cells involves redox-dependent signaling mechanisms. In light of some recent results showing that increased reactive oxygen species (ROS) production may have a prominent role in promoting cell apoptosis in response to TGF- $\beta,{ }^{17,23}$ we hypothesize that Nox4-dependent redox regulation may mediate TGF- $\beta$-induced endothelial cell apoptosis. Moreover, our previous studies in endothelial cells suggest that increased Nox4 expression may enhance cell proliferation (presumably a prosurvival effect) via activating the ERK1/2 MAPK pathway. ${ }^{24,25}$ In this study, therefore, we also attempted to reconcile these seemingly paradoxical effects of Nox4 in modulating endothelial cell apoptosis and survival.

In addition to apoptosis, some indirect evidence indicates that TGF- $\beta$ signaling may also have impacts on the specification of endothelial phenotypes. Specification of arterial or venous type of endothelium during development is under strict transcriptional control. ${ }^{26}$ It is thought that venous phenotype is the default state during endothelial differentiation, whereas activation of the Notch signaling pathway (which is downstream of vascular endothelial growth factor (VEGF) $A$ and sonic hedgehog) is obligatory for arterial differentiation. ${ }^{26,27}$ Some cell markers such as EphrinB2 and its receptor EphB4 are specifically expressed in arterial and venous endothelial cells, respectively. People have shown that lack of endoglin (an accessory receptor of TGF- $\beta$ ) or ALK1 results in vascular pathologies resembling a blood vessel anomaly known as arteriovenous malformation, ${ }^{28,29}$ which may be associated with disrupted arterial-venous specification of endothelium. ${ }^{30}$ Interestingly, mounting evidence indicates that ROSmediated signaling is an important regulator of stem or progenitor cell differentiation. ${ }^{31-33}$ However, little is known about the effects of ROS on arterial-venous specification of endothelial cells. Therefore, the second aim of this study is to explore the potential involvement of TGF- $\beta$-induced redox regulation in changes of the arterial and venous phenotype specification of endothelial cells.

\section{Results}

TGF- $\beta$ induces a moderate apoptotic response in human endothelial cells. We first characterized the effects of TGF- $\beta$ on apoptosis in endothelial cells. Human umbilical vein endothelial cells (HUVECs) were treated with TGF- $\beta$ for $24 \mathrm{~h}$ in the presence of serum. We found that TGF- $\beta$ significantly increased caspase $3 / 7$ activity in a concentration-dependent manner (Figure 1a). Next, we performed western blot analysis and showed that TGF- $\beta$ also triggered caspase 3 cleavage (Figure 1b). Using caspase $3 / 7$ activity assay, western blot and terminal deoxynucleotidyl transferase-mediated dUTP nick end labeling (TUNEL) assay, we further demonstrated that the effects of TGF- $\beta$ on apoptosis were time dependent, with the strongest effects being observed at 24 and $48 \mathrm{~h}$ (Figures 1c-f). To confirm our findings in HUVECs, we treated human dermal microvascular endothelial cells (HMVECs) with TGF- $\beta$ and showed that TGF- $\beta$ induced similar apoptotic reactions in a dose- and time-dependent manner (Figures $1 \mathrm{~g}$ and $\mathrm{h}$ ). These results have clearly shown that
TGF- $\beta$ has proapoptotic effects in human endothelial cells under current experimental conditions. In the following experiments, we used either 1 or $10 \mathrm{ng} / \mathrm{ml}$ of TGF- $\beta$ as the treatment condition.

TGF- $\beta$-induced apoptosis is dependent on ALK5 and ROS. To examine whether the ALK5 receptor was involved in TGF- $\beta$-induced apoptosis, HUVECs were pre-treated with the ALK5 inhibitor SB431542. Treatment with SB431542 at $2 \mu \mathrm{M}$ abolished the apoptotic response induced by TGF- $\beta$ as indicated by caspase $3 / 7$ activation and caspase 3 cleavage (Figures 2a and b). Moreover, we showed that SB431542 also prevented the collapse of mitochondrial membrane potential $(\Delta \Psi \mathrm{m})$ in response to TGF- $\beta$ as measured with JC-1 staining (Figure 2c and Supplementary Figure S1). Using $2^{\prime}, 7^{\prime}$-dichlorofluorescin diacetate (DCFH-DA) fluorescence, we found that TGF- $\beta$ treatment enhanced intracellular ROS production in HUVECs, and this effect could be blocked by SB431542 (Figure 2d and Supplementary Figure S1). To elucidate the role of ROS in TGF- $\beta$-induced apoptosis, we preincubated the cells with antioxidant compounds $N$-acetyl-L-cysteine (NAC) or EUK-134. We showed that both NAC and EUK-134 abrogated TGF- $\beta$-induced caspase $3 / 7$ activation (Figure 2e). Moreover, we confirmed that SB431542 had no effects on staurosporine-induced apoptosis (Supplementary Figure S1).

Nox4 is involved in mediating TGF- $\beta$-induced endothelial apoptosis. To elucidate the role of Nox4 in TGF- $\beta$-induced apoptosis, we first examined the effects of TGF- $\beta$ on Nox4 expression in HUVECs. We found that Nox4 expression was significantly increased following TGF- $\beta$ treatment (Figures $3 a$ and $b$ ) as measured by quantitative real-time PCR (qPCR). TGF- $\beta$ also increased Nox4 protein level as measured by western blot (Figures $3 c$ and d, Supplementary Figure S2A and B). The effects of TGF- $\beta$ on Nox4 expression were blocked by SB431542 (Figure 3e and Supplementary Figure S2C). Immunofluorescence experiments confirmed that TGF- $\beta$ increased the abundance of Nox4 protein, both in the nuclei and in the cytosol, and this effect was also blocked by SB431542 (Figure $3 f$ and Supplementary Figure S2D). To determine the role of Nox4 in TGF- $\beta$-induced apoptosis, cells were infected with lentiviruses encoding either a Nox4-specific short hairpin RNA (shRNA) or a control shRNA. The gene silencing efficacy of the Nox4 shRNA was confirmed by both qPCR and western blot (Supplementary Figure S3). It was revealed that Nox4 gene silencing blunted TGF- $\beta$-induced apoptosis (Figure $3 \mathrm{~g}$ ), as determined by caspase $3 / 7$ activity. To further confirm the results, we treated the cells with the pharmacological Nox inhibitor VAS2870, and showed that VAS2870 also blocked caspase 3/7 activation, caspase 3 cleavage and disruption of $\Delta \Psi \mathrm{m}$ induced by TGF- $\beta$ (Figures $3 \mathrm{~h}-\mathrm{j}$ and Supplementary Figure S4).

p38 MAPK mediates the redox-sensitive, TGF- $\beta$-induced endothelial apoptosis. To delineate the signaling mechanisms of TGF- $\beta$ - and Nox4-mediated apoptosis, we analyzed the activation of p38 and JNK pathways, which were redox sensitive. TGF- $\beta$ treatment increased phosphorylation of p38 


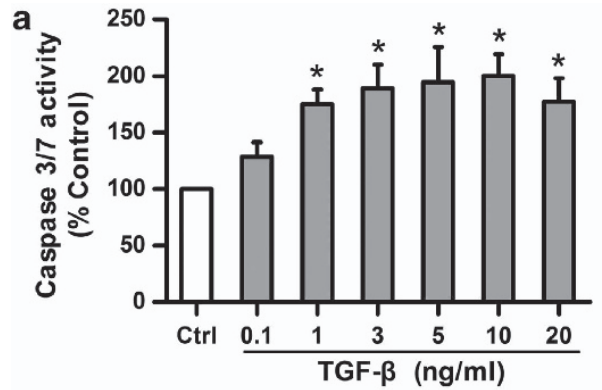

b
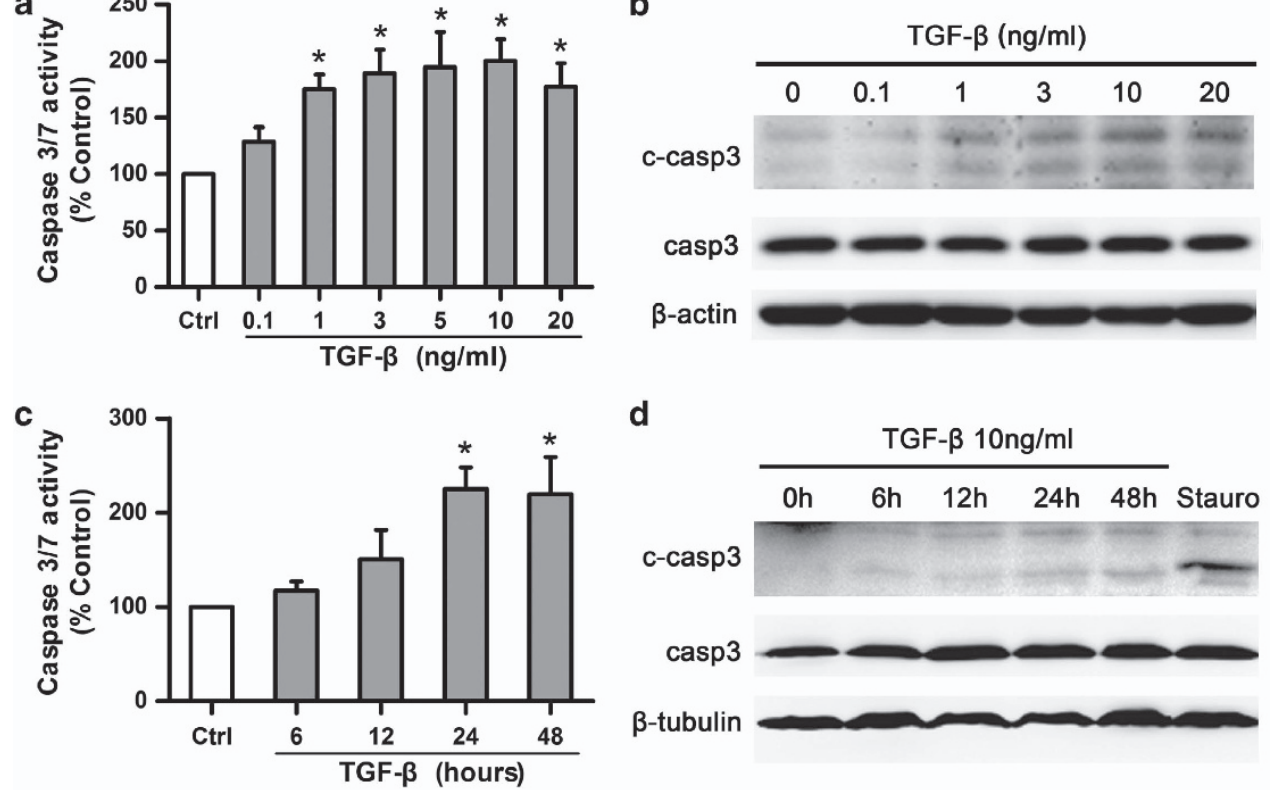

e
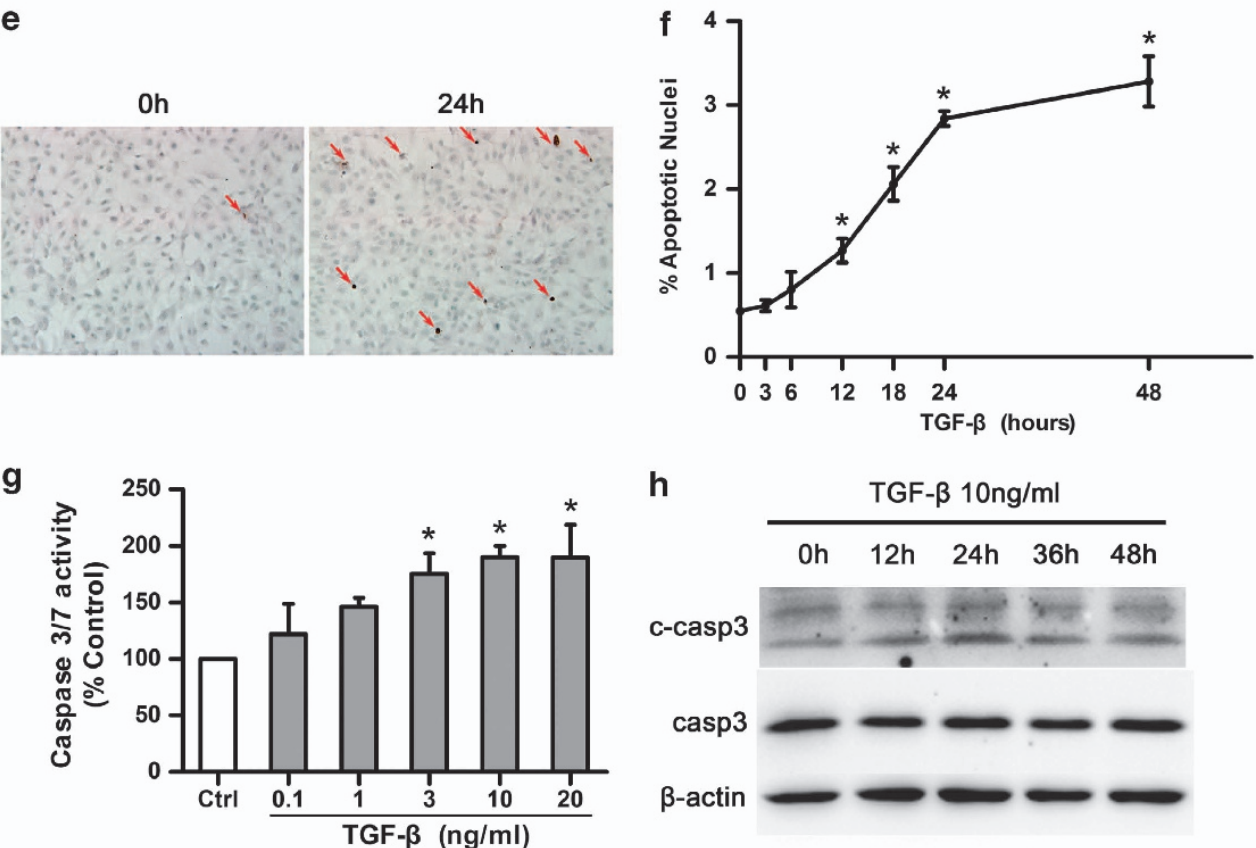

h

TGF- $\beta 10 \mathrm{ng} / \mathrm{ml}$

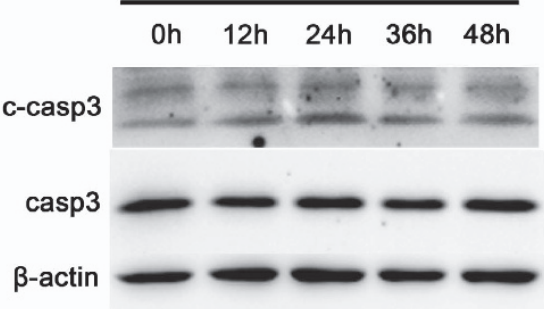

Figure 1 Effects of TGF- $\beta$ on apoptosis in cultured HUVECs (a-f) and HMVECs ( $\mathbf{g}$ and $\mathbf{h}$ ). (a) Effects of TGF- $\beta$ treatment (24 $\mathrm{h}$ ) at varying concentrations on caspase $3 / 7$ activation. (b) Effects of TGF- $\beta(24 \mathrm{~h}$ ) on caspase 3 activation (c-casp3, cleaved form of caspase 3 ). (c) Time course of TGF- $\beta$ (10 ng/ml) effects on caspase $3 / 7$ activation. (d) Time course of TGF- $\beta(10 \mathrm{ng} / \mathrm{ml}$ ) effects on caspase 3 cleavage. Staurosporine (Stauro, $100 \mathrm{nM}$ for $1 \mathrm{~h}$ ) was used as a positive control. (e) Representative images showing apoptotic cells (arrows) induced by TGF- $\beta(10 \mathrm{ng} / \mathrm{ml}$ for $24 \mathrm{~h}$ ) detected with TUNEL assay. (f) Quantitative data of TGF- $\beta$-induced apoptosis detected with TUNEL assay (values averaged from 10 random fields from four independent experiments each). Data are mean \pm S.E.M. ${ }^{*} P<0.05$ versus control, one-way ANOVA, $n=4-8$. (g) Effects of TGF- $\beta(24 \mathrm{~h}$ ) at different concentrations on caspase $3 / 7$ activity in HMVECs. (h) Time course of TGF- $\beta$ ( $10 \mathrm{ng} / \mathrm{ml})$ effects on caspase 3 cleavage in HMVECs. All western blot experiments were repeated at least twice

from $12 \mathrm{~h}$, and the level of p38 phosphorylation remained elevated up to $48 \mathrm{~h}$ as compared with untreated cells (Figure 4a). In contrast, phosphorylation of JNK was only transiently increased around $12 \mathrm{~h}$ (Figure $4 \mathrm{a}$ ). TGF- $\beta$ also moderately increased phosphorylation of ERK1/2. To clarify whether p38 or JNK was required for TGF- $\beta$-induced apoptosis, we treated the cells with specific kinase inhibitors and demonstrated that inhibition of the p38 pathway with SB202190 blocked the proapoptotic effects of TGF- $\beta$, whereas the JNK Inhibitor II had no significant effects (Figures $4 b$ and $c$ ). We further confirmed these results by knocking down p38 and JNK expression with specific siRNAs (Supplementary Figure S5). To determine whether activation of p38 and JNK pathways were redox- and Nox4-dependent, 
a

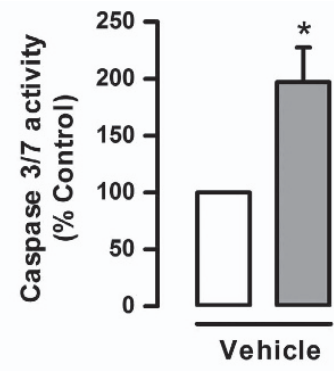

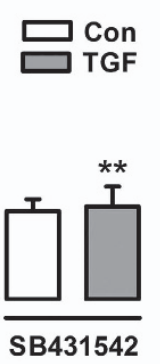

b
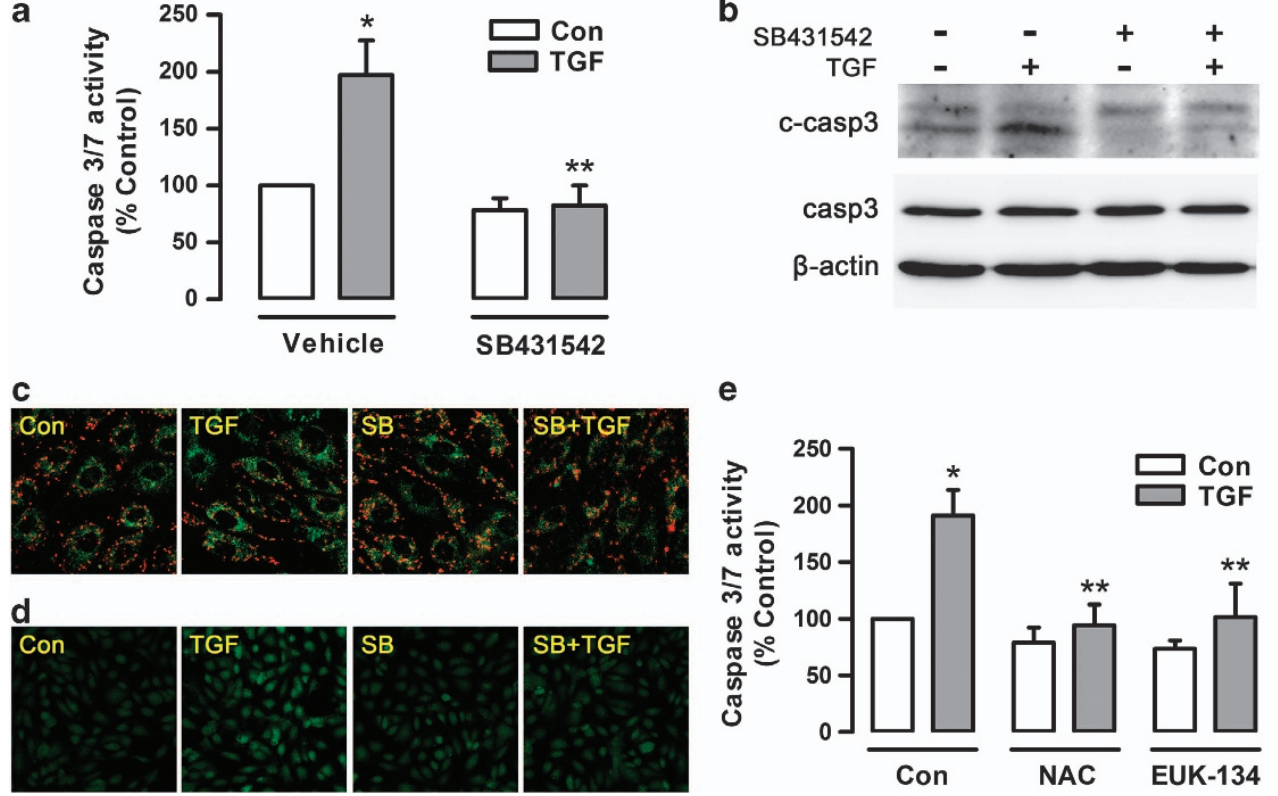

e

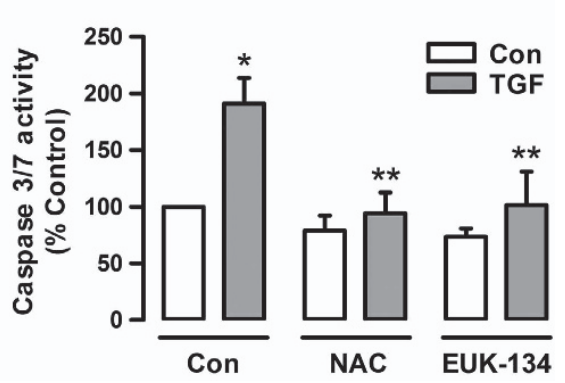

Figure 2 Roles of ALK5 receptor and ROS in TGF- $\beta$-induced apoptosis in HUVECs. (a) Effects of the ALK5 inhibitor SB431542 (2 $\mu$ M) on TGF- $\beta$ (10 ng/ml for $24 \mathrm{~h})$ induced caspase $3 / 7$ activation. (b) Effects of SB431542 on TGF- $\beta$-induced caspase 3 cleavage. (c) Effects of SB431542 on TGF- $\beta$-induced $\Delta \Psi \mathrm{m}$ depression (reduced red fluorescence) as detected with JC-1 staining (representative images of three independent experiments). The red fluorescence specifically labeled the mitochondria. (d) Effects of TGF- $\beta$ and SB431542 on intracellular ROS production detected with DCFH-DA (green fluorescence). (e) Effects of antioxidant compounds NAC (1 mM) and EUK-134 $(100 \mu \mathrm{M})$ on TGF- $\beta$-induced caspase $3 / 7$ activation. Data are mean \pm S.E.M. ${ }^{*} P<0.05$ versus control (Con), ${ }^{\star *} P<0.05$ versus TGF alone, one-way ANOVA ( $\left.n=3-5\right)$

we first pre-treated the cells with NAC. We found that NAC completely blocked the effect of TGF- $\beta$ on p38 phosphorylation (Figure 4d). However, NAC per se somehow increased the basal level of JNK phosphorylation, whereas the TGF- $\beta$ effect on JNK phosphorylation in the presence of NAC was not significant (Figure 4e), indicating that activation of both p38 and JNK were redox sensitive. Moreover, we showed that inhibition of the Nox4 function with VAS2870 diminished TGF- $\beta$-induced p38 phosphorylation (Figure 4f). These results together indicate that p38 is responsible for mediating TGF- $\beta$-induced, Nox4-dependent endothelial cell apoptosis. In contrast to MAPKs, TGF- $\beta$ had no effects on Akt phosphorylation either under the basal condition or in the presence of NAC or VAS2870 (Figure 4g).

Ectopically overexpressed Nox4 is protective against endothelial apoptosis. Our previous study showed that overexpression of Nox4 in endothelial cells produced an antiapoptotic action. ${ }^{24}$ To clarify the mechanisms of the divergent effects of ectopic and endogenous Nox4 on endothelial apoptosis, we first confirmed our previous findings using lentivirus-mediated Nox4 overexpression (vNox4). We demonstrated that vNox4 suppressed both of the basal level of and serum starvation-induced apoptosis in HUVECs (Figure 5a). In addition, we showed that overexpression of Nox4 (using adenovirus) also reduced the apoptosis induced by staurosporine (Figure $5 b$ ). Also, we found that TGF- $\beta$ failed to induce endothelial apoptosis following Nox4 overexpression (data not shown). Next, we examined the effects of vNox4 on the prosurvival mediators Akt and ERK1/2. We showed that phosphorylation of Akt was dose-dependently increased by vNox4 treatment (Figure 5c).
However, vNox4 had no significant effects on ERK1/2 phosphorylation as compared with control viruses, whereas the control virus somehow increased the basal level of ERK $1 / 2$ phosphorylation (Figure 5d). Treatment with Akt inhibitor VIII or wortmannin significantly attenuated the antiapoptotic effects of vNox4, whereas treatment with U0126 produced no effects (Figures $5 \mathrm{e}-\mathrm{g}$ ). We also confirmed that knocking down of Akt with siRNA partially blocked the inhibitory effects of vNox4 on apoptosis (Supplementary Figure S6). To clarify whether there was a difference in the subcellular distribution between ectopic and endogenously expressed Nox4, we performed immunofluorescence in vNox4-treated cells. We found that vNox4 increased the Nox4 protein level in both of the cytoplasm and nuclei (Figure $5 \mathrm{~h}$ ), a pattern that was similar to that following TGF- $\beta$ treatment (see Figure $3 \mathrm{f}$ ). Given that TGF- $\beta$ did not change the phosphorylation level of Akt, these data suggested that Akt activation by vNox4 might be responsible for the differential effects of the endogenous and ectopic Nox4 on apoptosis.

vNox4 suppresses PTP1B activity and enhances VEGFR activation. To understand the signaling mechanisms by which vNox4 activated Akt, we first examined whether inhibition of protein tyrosine phosphatase 1B (PTP1B) or PTEN, two ROS-sensitive phosphatases involved in mediating intracellular redox signaling, ${ }^{34}$ affected the phosphorylation of Akt. Figures $6 a$ and $b$ demonstrated that treatment with the PTP1B inhibitor, but not PTEN inhibitor, increased Akt phosphorylation in resting endothelial cells. This effect of PTP1B inhibition was comparable to that induced by VEGF, whereas VEGF did not further increase Akt phosphorylation in the presence of PTP1B inhibitor (Figure 6c). In contrast, 
a

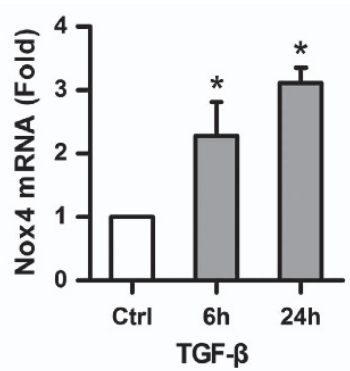

b

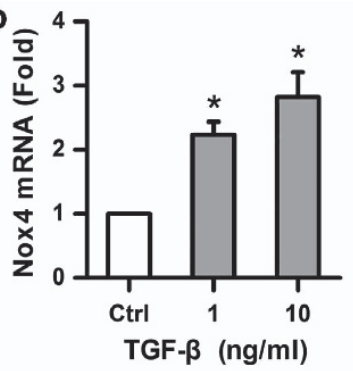

C

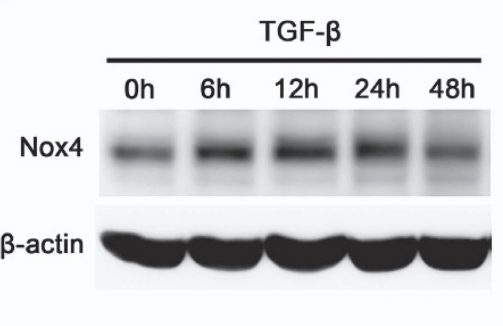

e Con TGF SB SB+TGF

Nox4

$\beta$-actin

$\beta$-actin
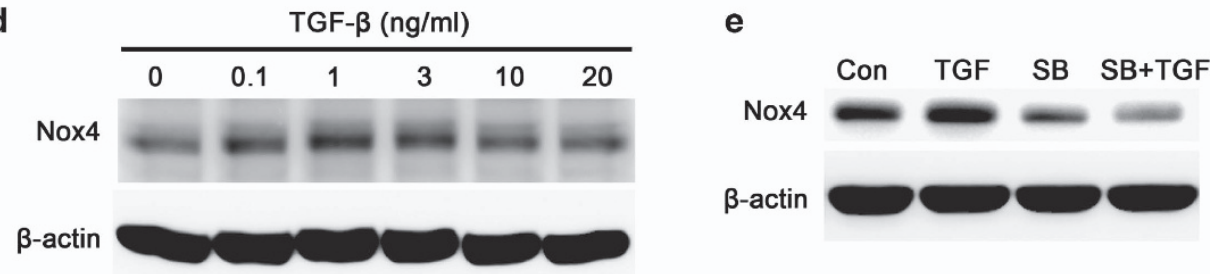

f
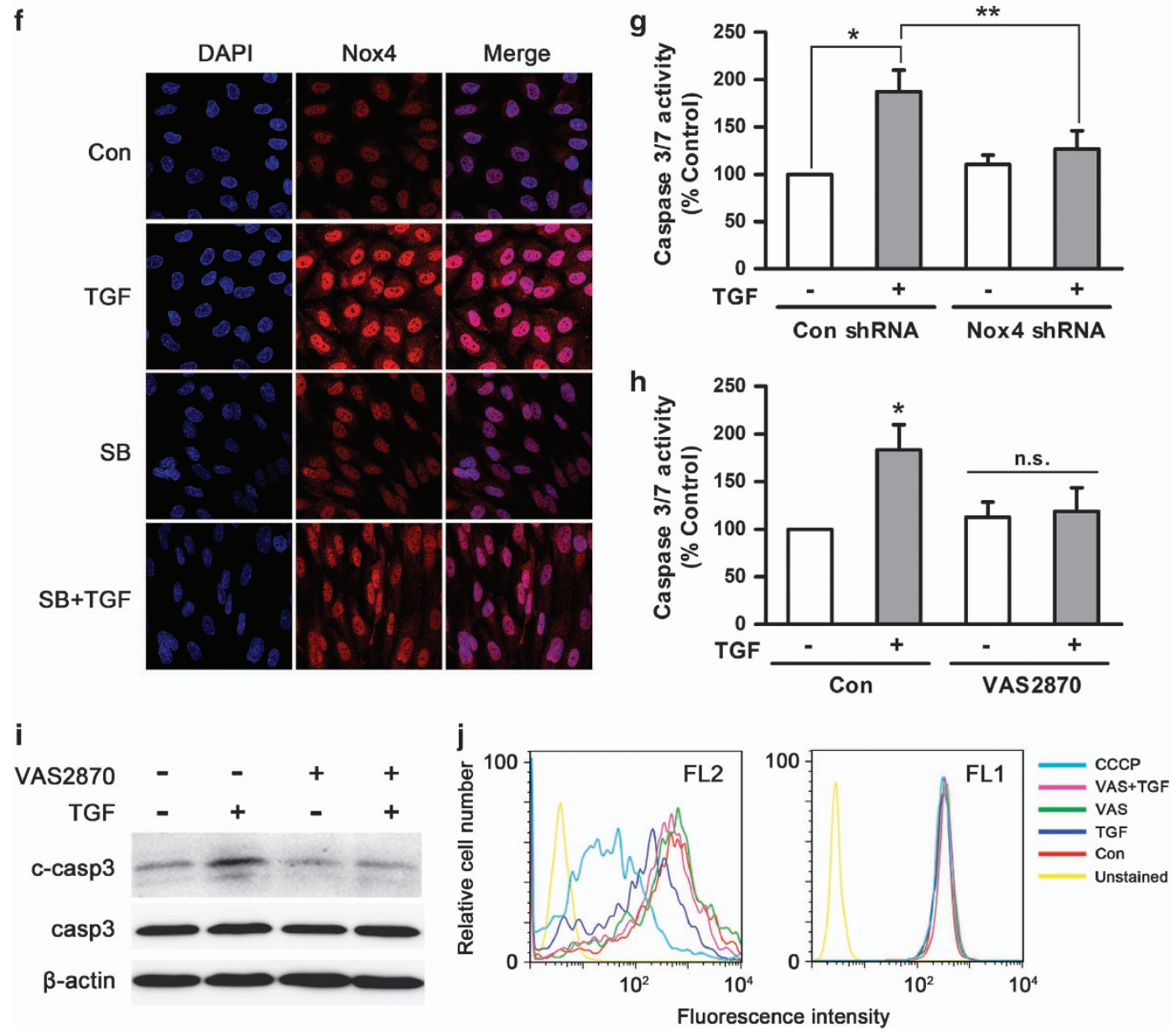

Figure 3 Role of Nox4 in TGF- $\beta$-induced apoptosis in HUVECs. ( $\mathbf{a}$ and $\mathbf{b}$ ) Effects of TGF- $\beta$ treatment on Nox4 expression measured with qPCR. TGF- $\beta$ of 1 ng $/ \mathrm{ml}$ was used for the time course experiment. (c) Western blot showing the effects of TGF- $\beta(1 \mathrm{ng} / \mathrm{ml}$ ) on Nox 4 protein expression. (d) Effects of TGF- $\beta$ at different concentrations on Nox4 protein expression. (e) Effects of SB431542 on TGF- $\beta$-induced Nox4 expression. (f) Immunofluorescent microscopic images showing the effects of TGF- $\beta$ (1 ng/ml for $24 \mathrm{~h}$ ) and SB431542 $(2 \mu \mathrm{M})$ on Nox4 (red color) expression and localization in HUVECs. (g) Effects of Nox4 gene silencing with shRNA on TGF- $\beta$-induced caspase 3/7 activation. (h) Effects of the Nox inhibitor VAS2870 $(1 \mu \mathrm{M})$ on TGF- $\beta$-induced caspase $3 / 7$ activation. (i) Western blot showing the effects of VAS2870 on TGF- $\beta$-induced caspase 3 cleavage. (j) Flow cytometric analysis of changes in $\triangle \Psi \mathrm{m}$ in cells treated with TGF- $\beta \pm$ VAS2870. Values of the red (FL2) to green (FL1) fluorescence intensity ratio in each group (normalized to control) were: Con $100 \%$; TGF- $\beta 57.9 \pm 14.0 \%$; VAS $87.4 \pm 9.0 \%$; VAS + TGF: $94.1 \pm 10.1 \%$. CCCP (carbonyl cyanide m-chlorophenylhydrazone, $10 \mu \mathrm{M}$ ), a mitochondrial uncoupling agent, was used as a positive control. All data are mean \pm S.E.M. Asterisks indicate $P<0.05$, one-way ANOVA ( $n=3-4)$. NS indicates no significance 
a

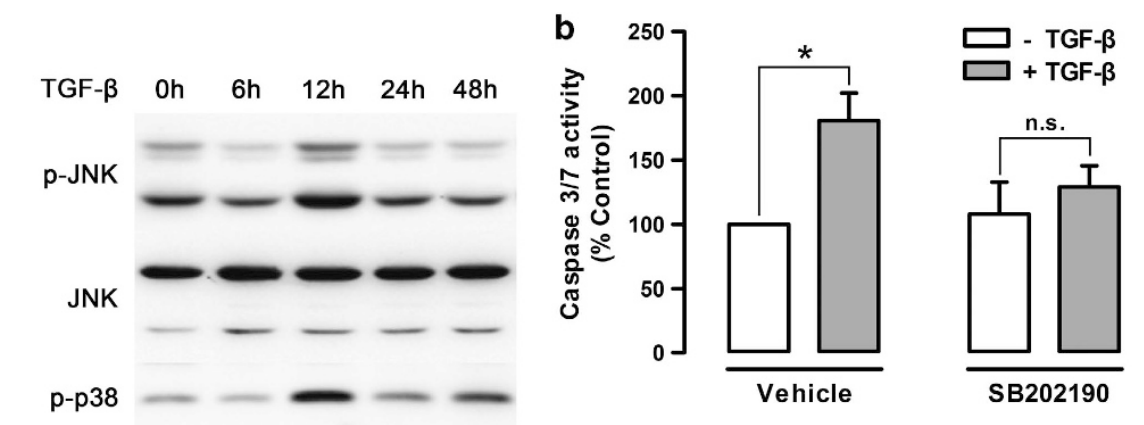

p38 $-\infty$
p-ERK1/2 $= \pm=$

ERK1/2

$\beta$-actin
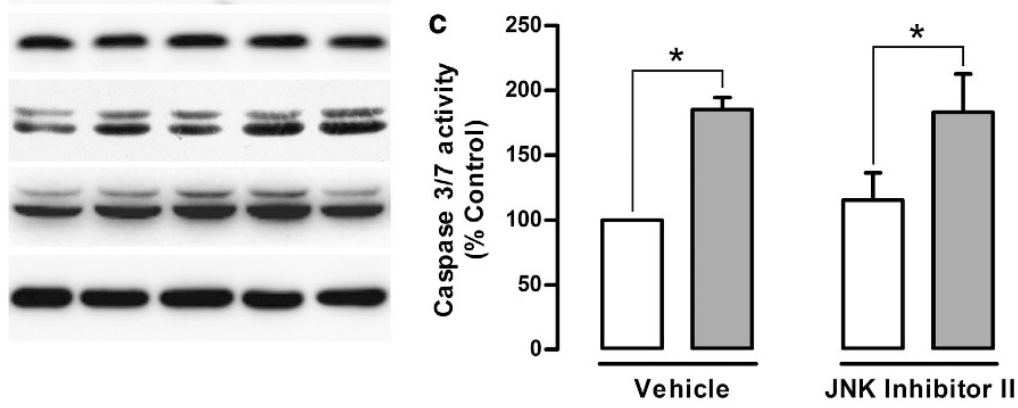

d
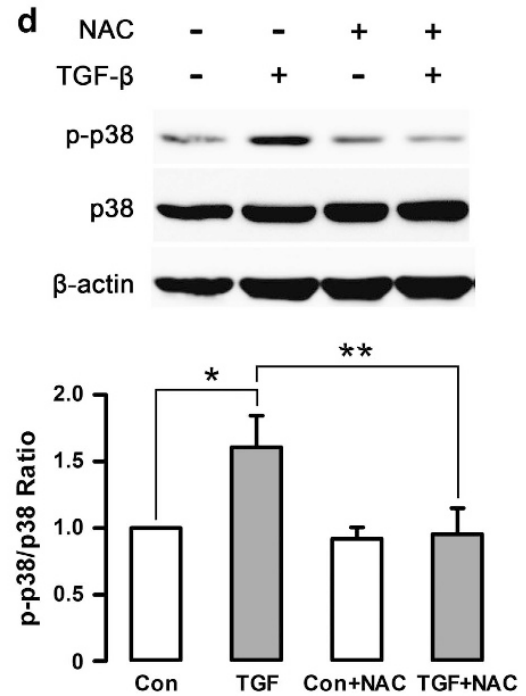
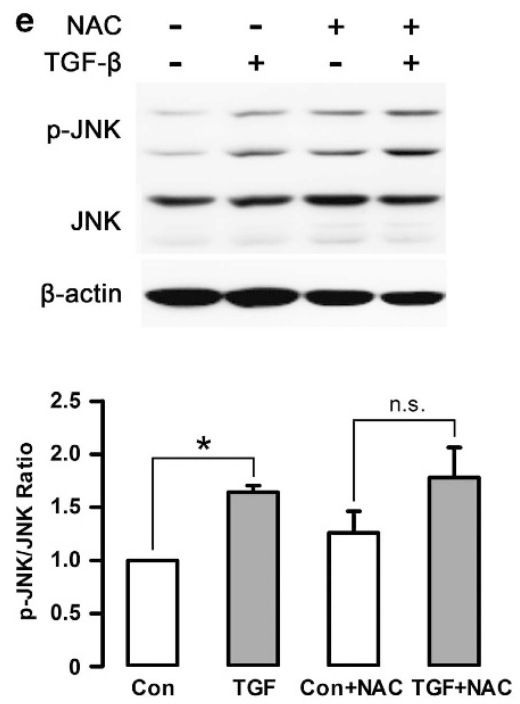

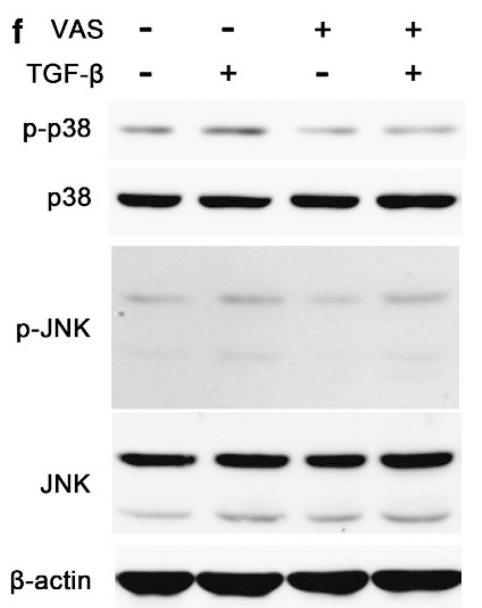

g $\begin{array}{rrrrrrrrr}\text { VAS } & - & - & - & - & - & - & + & + \\ \text { NAC } & - & - & + & + & - & - & - & - \\ \text { TGF- } \beta & - & + & - & + & - & + & - & +\end{array}$ p-Akt Akt

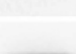
$\beta$-actin 
VEGF similarly induced Akt phosphorylation in the absence and presence of the PTEN inhibitor (Figure 6d). To further clarify the impacts of Nox4 overexpression on PTP1B function, we measured the phosphatase activity in immunoprecipitated PTP1B in control and Nox4-overexpressing cells. We showed that Nox4 overexpression suppressed PTP1B activity (Figure 6e). To confirm that the inhibition of PTP1B activity was redox sensitive, we added a reducing agent dithiothreitol (DTT) in all samples, and showed that the effect of Nox4 on PTP1B activity was abolished by DTT (Figure 6e). As PTP1B was a negative regulator of VEGF receptor (VEGFR) signaling, we then examined whether vNox4 or PTP1B inhibitor modulated VEGFR2 phosphorylation. Immunoprecipitation with anti-VEGFR2 or anti-phosphotyrosine followed by western blot analysis revealed that inhibition of PTP1B or overexpression of Nox4 enhanced VEGFR2 phosphorylation (Figures $6 f$ and g). Similar to the effects on Akt phosphorylation, VEGF only increased the basal level of VEGFR2 phosphorylation, but had smaller effects on VEGFR2 phosphorylation in the presence of vNox4 or PTP1B inhibitor.

TGF- $\beta$ stimulates expression of arterial markers in HUVECs. The effects of TGF- $\beta$ on expression of arterial and venous markers were determined by qPCR. TGF- $\beta$ upregulated expression of the arterial marker EphrinB2 (Figure 7a), although we did not observe a significant change in the EphrinB2 protein level (Figure 7b). In contrast, TGF- $\beta$ had no effects on expression of the venous maker EphB4 (Figure 7a). To further confirm whether TGF- $\beta$ promoted a phenotypic shift toward the arterial type of endothelium, we characterized the expression profile of various Notch receptors (Notch1 and Notch4) and ligands (Jagged1 and DLL4), and the Notch target gene (HEY1). As shown in Figure 7c, TGF- $\beta$ significantly increased the expression levels of all of these Notch signaling markers. The increased expression of DLL4, Notch1 and Jagged1 were also confirmed with western blot (Figure $7 \mathrm{~d}$ and Supplementary Figure S7). Moreover, we demonstrated that TGF- $\beta$ treatment also increased the amount of Notch intracellular domain (NICD) (Figure 7e and Supplementary Figure S7), and stimulated nuclear translocation of NICD as detected with immunofluorescence and western blot (Figure $7 f$ and Supplementary Figure S7), indicating an enhanced Notch signaling. Of note, we found that the effects of TGF- $\beta$ on expression of the arterial markers were cell type specific, as we did not observe any significant effects of TGF- $\beta$ on EphrinB2, EphB4, Notch1, Notch4, Jagged1 or HEY1 in HMVECs (Supplementary Figure S8).

TGF- $\beta$-induced arterial marker expression is redoxdependent. To clarify whether TGF- $\beta$-induced arterial marker expression in HUVECs was redox dependent, we pre-treated the cells with NAC, and demonstrated that in the presence of NAC, TGF- $\beta$ showed no significant effects on the arterial marker expression as compared with cells treated with TGF- $\beta$ alone (Figure 8a). Consistently, we found that application of exogenous $\mathrm{H}_{2} \mathrm{O}_{2} \quad(100 \mu \mathrm{M}$ for $24 \mathrm{~h})$ mimicked the effects of TGF- $\beta$ on expression of the arterial markers (Figure 8b). Importantly, we demonstrated that TGF- $\beta$-induced effects on expression of Notch1, Jagged1, HEY1 and EphrinB2 were diminished in cells pre-treated with the lentivirus expressing Nox4 shRNA (Figure 9).

\section{Discussion}

In this study, we showed that TGF- $\beta$ produced a moderate apoptotic response in human endothelial cells in culture. Using two different types of endothelial cells, we provided evidence showing that induction of Nox4 expression and subsequent increase in ROS production mediated TGF- $\beta$ induced endothelial apoptosis. Nox4 is the most important ROS-producing enzyme in endothelial cells. ${ }^{35,36}$ We showed that TGF- $\beta$ specifically upregulated the expression of Nox4, and this responsiveness of Nox4 expression to TGF- $\beta$ is consistent with previous studies in other cell types. ${ }^{15-17,23}$ Using both of a pharmacological inhibitor of Nox4 and RNA interference, we showed that blocking Nox4 expression or function attenuated the proapoptotic effects of TGF- $\beta$. Our results are supported by similar findings in hepatocytes and lung epithelial cells. ${ }^{17,23}$ Moreover, we confirmed our results with different antioxidant compounds, which also rescued TGF- $\beta$-induced apoptosis. In contrast to endothelial cells, TGF- $\beta$-induced Nox4 expression has been shown to stimulate proliferation in pulmonary vascular smooth muscle cells, ${ }^{15}$ consistent with the notion that the effects of NADPH oxidasemediated signaling on cellular functions are cell type specific. $^{34}$ In addition, there is increasing evidence showing that TGF- $\beta$-stimulated Nox4 expression is tightly involved in fibrotic reactions in fibroblasts and fibrogenic trans-differentiation of mesenchymal cells. ${ }^{16,37,38}$ These findings taken together strongly support the case that Nox4 may work as an important signaling effector in mediating TGF- $\beta$-induced cellular effects.

ROS may trigger apoptosis via multiple mechanisms, of which the MAPK pathways are well-documented redoxsensitive mediators involved in modulating cell apoptosis. ${ }^{39}$ In this study, we found that p38, but not JNK, was critical in mediating endothelial apoptosis induced by TGF- $\beta$. This observation is consistent with other studies showing a similar proapoptotic role of p38 in TGF- $\beta$-induced apoptosis. ${ }^{21,40,41}$ People showed that in response to increased ROS production, activation of p38 directly affected phosphorylation and activation of some proapoptotic $\mathrm{Bcl}-2$ family proteins such as Bim and Bax. ${ }^{42,43}$ In line with this mechanism, we demonstrated that TGF- $\beta$ treatment induced disruption of the $\Delta \Psi \mathrm{m}$, an effect that was diminished by the Nox4 inhibitor VAS2870. Notably, a direct link between Nox4-dependent ROS

Figure 4 Role of MAPKs in TGF- $\beta$ - and ROS-induced apoptosis in HUVECs. (a) Effects of TGF- $\beta(10 \mathrm{ng} / \mathrm{ml})$ on phosphorylation of JNK, p38 and ERK1/2 MAPKs. (b and c) Effects of the p38 inhibitor (SB202190) and JNK inhibitor II (all of $1 \mu \mathrm{M}$ ) on TGF- $\beta$-induced caspase 3/7 activation. (d and e) Western blots showing the effects of NAC $(1 \mathrm{mM}$ ) on TGF- $\beta$-induced phosphorylation of $\mathrm{p} 38$ and JNK. Quantitative densitometry data were shown by the bar graphs below. (f) Effects of VAS2870 on TGF- $\beta$-induced phosphorylation of $\mathrm{p} 38$ and JNK. (g) Effects of TGF- $\beta$ on Akt phosphorylation in the presence or absence of NAC and VAS2870. All data are mean \pm S.E.M. Asterisks indicate $P<0.05$, one-way ANOVA $(n=4-5)$. NS indicates no significance 
a

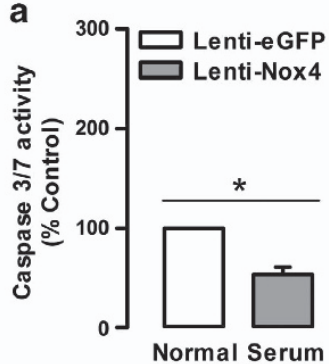

c

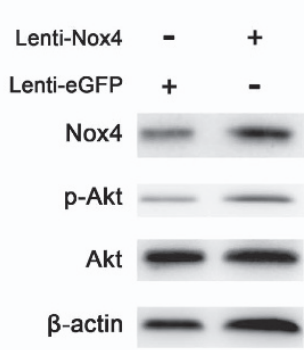

MOI $=5$

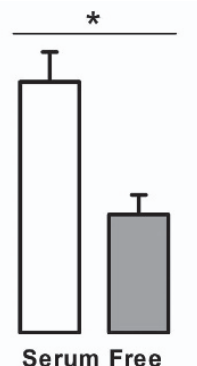

Serum Free

b

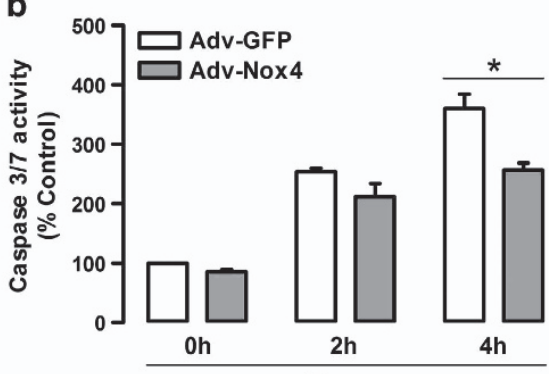

Stauro

d

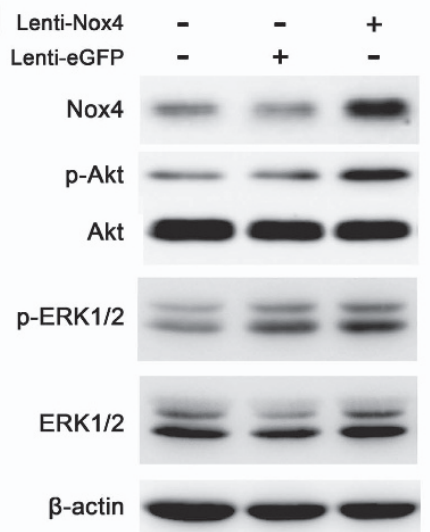

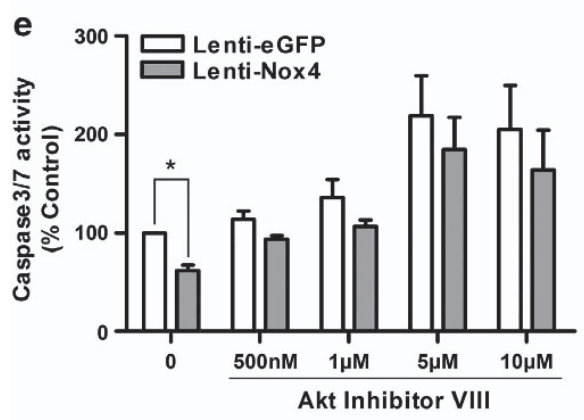

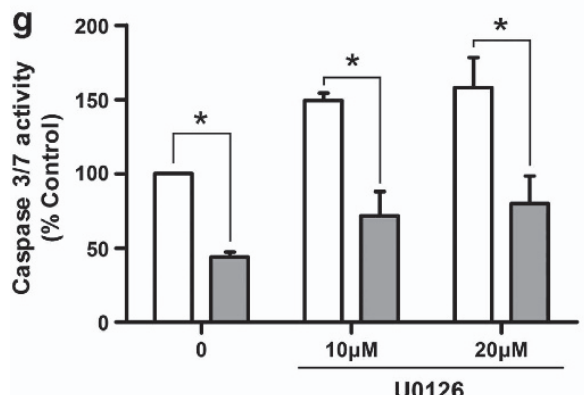

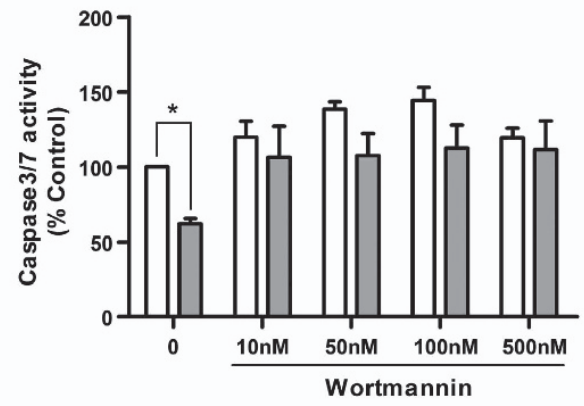

h

DAPI

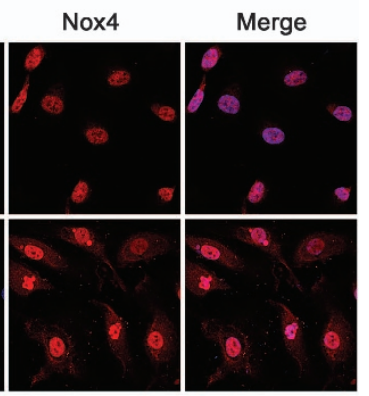

Figure 5 Effects of Nox4 overexpression mediated by either lentiviral or adenoviral vector-based gene transfer on endothelial cell apoptosis. Viruses expressing GFP was used as control. (a) Effects of Nox4 overexpression on caspase $3 / 7$ activity in cells cultured with $5 \%$ serum and cells with serum starvation. (b) Effects of Nox4 overexpression on staurosporine (Stauro, $100 \mathrm{nM}$ )-induced apoptosis. (c) Dose-dependent effects of Lenti-Nox4 on Akt phosphorylation. (d) Western blots showing that Lenti-Nox4 increased Akt phosphorylation, but had minor effects on ERK1/2 phosphorylation. (e-g) Effects of Akt inhibitor VIII, wortmannin and U0126 at varying concentrations on the inhibitory action of Lenti-Nox4 on cell apoptosis as measured by caspase 3/7 activity. (h) Immunofluorescence showing the intracellular distribution of Nox4 (red) following Lenti-Nox4 treatment. Nuclei were counterstained with DAPI. All numeric data are expressed as mean \pm S.E.M., ${ }^{\star} P<0.05$, one-way ANOVA $(n=3-5)$

production and activation of $\mathrm{p} 38$ has also been demonstrated in endothelial cells by other groups. ${ }^{44}$ How ROS activate p38 in endothelial cells is not clear. In other cells, there is evidence suggesting that NADPH oxidase-mediated p38 activation requires apoptosis signal regulating kinase-1, a redoxsensitive member of the MAPK kinase kinases family. ${ }^{45,46}$ However, whether this kinase has a role in mediating TGF- $\beta$ induced endothelial apoptosis is to be confirmed. 
a

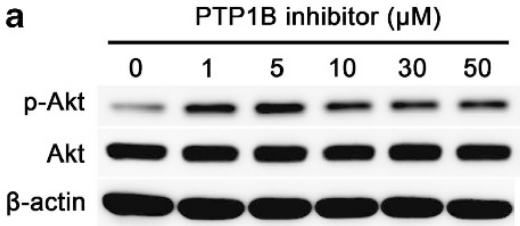

b

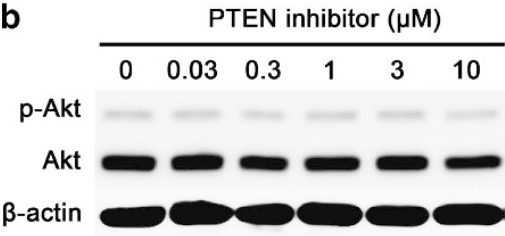

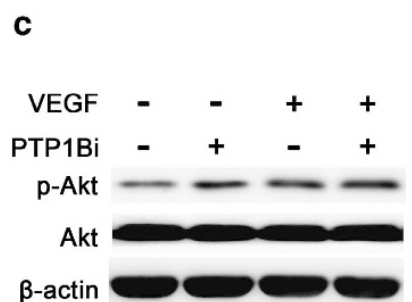

d
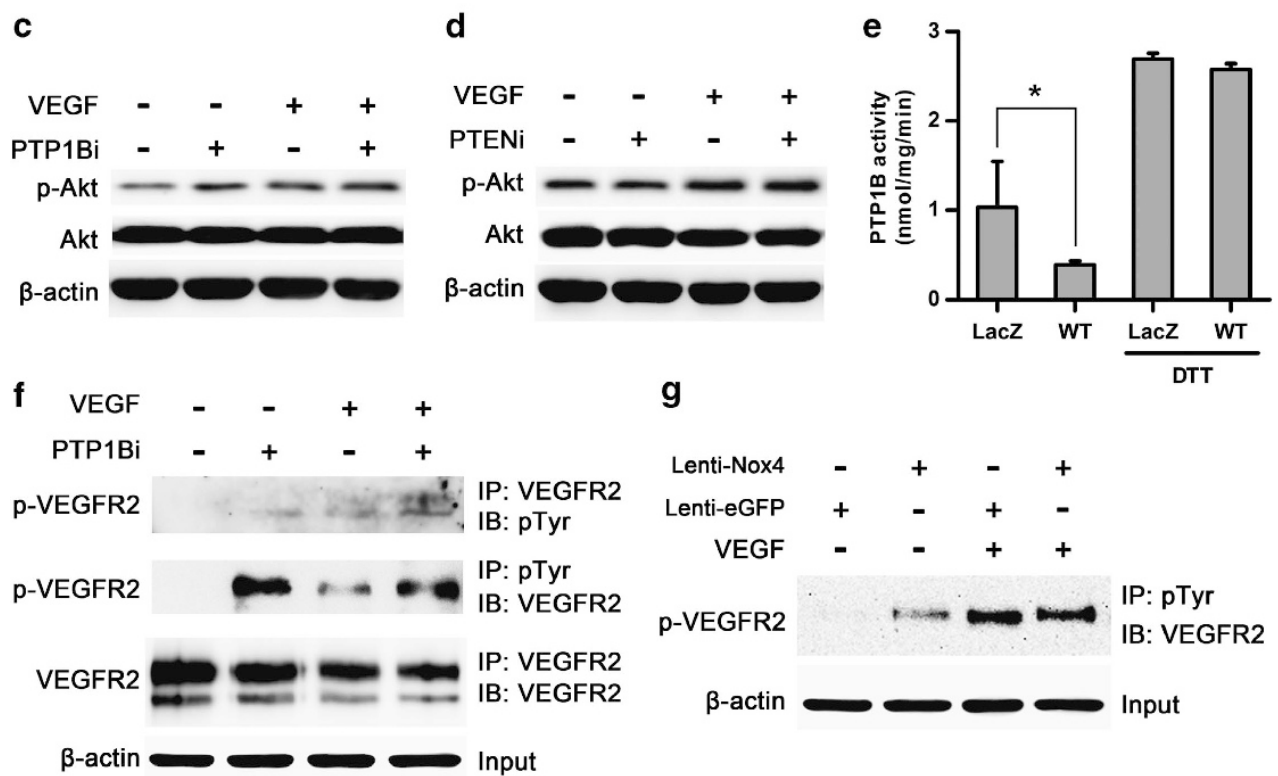

g

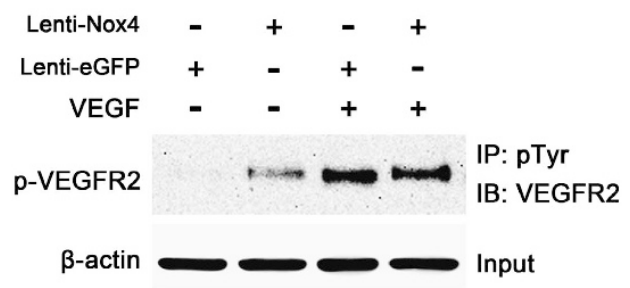

Figure 6 Roles of PTP1B and PTEN in modulating VEGFR signaling and Akt phosphorylation. (a and $\mathbf{b})$ Concentration-dependent effects of the inhibitors of PTP1B and PTEN (incubation for $24 \mathrm{~h}$ ) on basal Akt phosphorylation. (c and d) Effects of the PTP1B inhibitor (PTP1Bi, $10 \mu \mathrm{M})$ and PTEN inhibitor (PTENi, $1 \mu \mathrm{M})$ on VEGF165 (10 ng/ml for $20 \mathrm{~min}$ )-induced Akt phosphorylation. (e) Effects of overexpression of wild-type Nox4 on PTP1B phosphatase activity. DTT was added to the phosphatase reaction buffer as a reducing agent. ${ }^{*} P<0.05$, unpaired $t$-test $(n=4)$. (f) Effects of the PTP1B inhibitor on basal and VEGF-induced VEGFR2 phosphorylation. Cell lysates were immunoprecipitated (IP) with either an anti-VEGFR2 or anti-phospho-tyrosine (pTyr) antibody, followed by western blot (IB) analysis to detect tyrosine phosphorylated VEGFR2 (p-VEGFR2). The $\beta$-actin was used as an input control. (g) Effects of Lenti-Nox4 on basal and VEGF-induced VEGFR2 phosphorylation. All IP experiments were repeated for three times

In contrast to the observed proapoptotic effects of Nox4 in TGF- $\beta$-stimulated endothelial cells, our previous studies and those from other groups indicate that increased Nox4 expression in endothelial cells may also have an enhancing effect on cell viability. ${ }^{24,25,47}$ Moreover, we confirmed that forced overexpression of Nox4 indeed exhibited inhibitory effects on basal and drug-induced apoptosis, indicating that the endogenous and ectopically expressed Nox4 might have divergent biological functions. Supporting this observation, discrepant roles of endogenous and overexpressed Nox4 have also been suggested by other studies. ${ }^{18,48}$ To understand the mechanism for this phenomenon, we examined the status of potential prosurvival pathways, and found that vNox4 significantly enhanced Akt phosphorylation, whereas TGF- $\beta$ had little effect. Moreover, we demonstrated that inhibition of Akt activation blunted the antiapoptotic effects of vNox4. The differential effects of TGF- $\beta$ and Nox4 overexpression can be explained by the finding that both of the mRNA and protein expression levels of Nox4 following viral vector transfection are markedly higher than those induced by TGF- $\beta$ treatment, whereas the threshold of ROS level required for Akt activation is higher than that produced by TGF- $\beta$. However, we did not observe any obvious difference in subcellular localization of Nox4 after treatments with TGF- $\beta$ or vNox4, suggesting that the location of ROS production had a minor role. Interestingly, inhibition of Akt did not reverse the antiapoptotic effect of Nox4 overexpression to a proapoptotic action, indicating that other compensating mechanism(s) might also be activated by ectopic Nox4. However, our results did not support that the ERK1/2 pathway had a major role in modulating endothelial apoptosis after Nox4 overexpression.

PTP1B is a well-established redox sensor that can mediate ROS-induced intracellular signaling. ${ }^{34}$ We showed that overexpression of Nox4 significantly suppressed the PTP1B phosphatase activity. Moreover, using a pharmacological inhibitor of PTP1B, we showed that inhibition of PTP1B mimicked the effects of vNox4 on the phosphorylation levels of VEGFR2 and Akt. In endothelial cells, there is evidence suggesting that PTP1B negatively regulates VEGFRmediated signaling. ${ }^{49}$ In our study, we clearly demonstrated that vNox4 and PTP1B inhibitor both increased the level of VEGFR2 phosphorylation, indicating that Nox4-induced Akt activation was likely to be downstream of enhanced VEGFR signaling. These results strongly suggest that oxidative inactivation of PTP1B causes enhanced VEGFR phosphorylation and subsequent Akt activation, which mediates the prosurvival effects of Nox4 overexpression. Interestingly, we found that Nox4 overexpression or the PTP1B inhibitor 


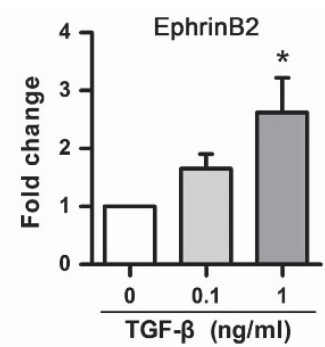

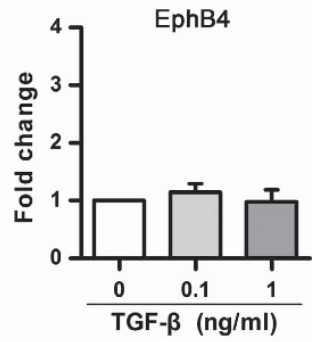

b

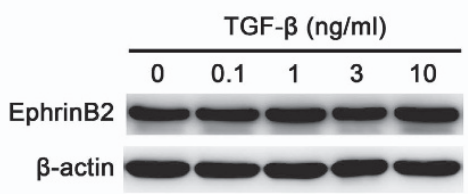

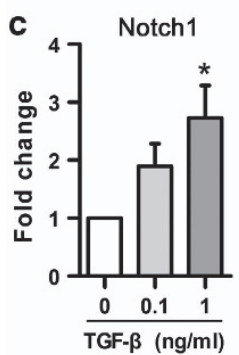
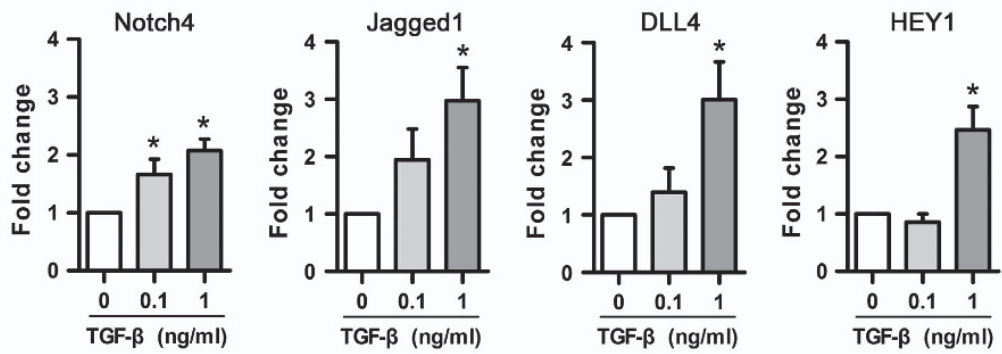

d

f
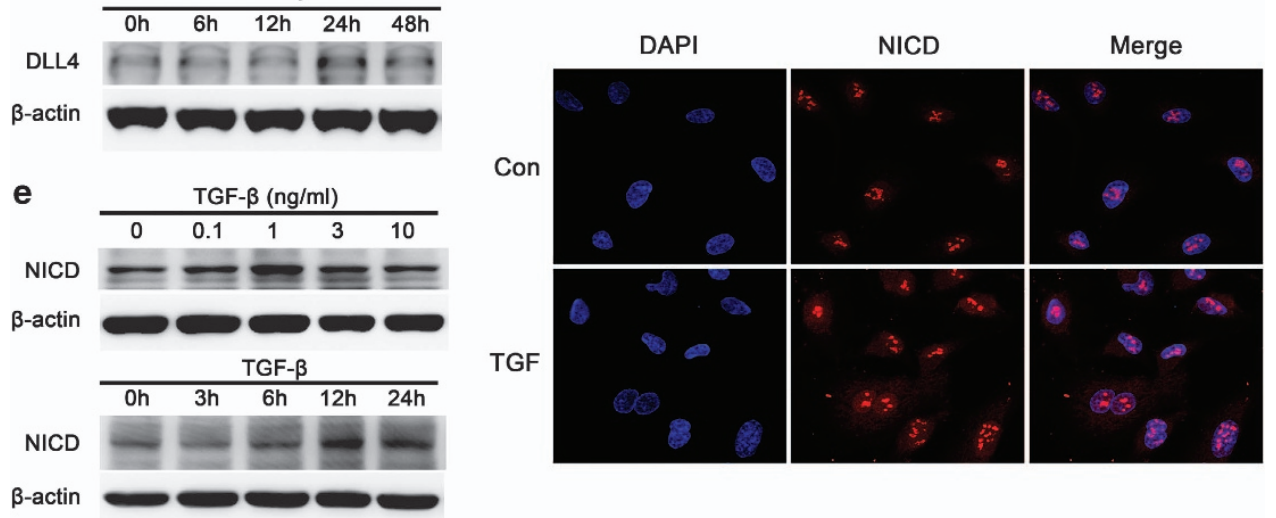

Figure 7 Effects of TGF- $\beta$ on the expression of various arterial-venous markers in HUVECs. (a) Effects of TGF- $\beta$ (24 h) on the expression of EphrinB2 and EphB4 measured with qPCR. (b) Effects of TGF- $\beta$ on the protein expression level of EphrinB2. (c) Expression profiles of Notch receptors (Notch1 and Notch4), ligands (Jagged1 and DLL4) and Notch target gene (HEY1) in response to TGF- $\beta$ treatment measured with qPCR. (d) Time course of the effect of TGF- $\beta$ (1 ng/ml) on DLL4 protein level. (e) Western blots showing the increased level of NICD following TGF- $\beta$ treatment. TGF- $\beta$ of $1 \mathrm{ng} / \mathrm{ml}$ was used for the time course experiment. (f) Immunofluorescent images of $\mathrm{NICD}$ (red) and nuclei (blue) in cells with and without TGF- $\beta(1 \mathrm{ng} / \mathrm{ml}$ for $24 \mathrm{~h})$ treatment. All numeric data are mean \pm S.E.M., * $P<0.05$ versus control, one-way ANOVA $(n=4)$. Western blot and immunofluorescent images were from three independent experiments

triggered VEGFR2 phosphorylation in the absence of VEGF ligand. These data suggest that in endothelial cells, PTP1B activity has a gate-keeping role in regulating VEGFR signaling under resting conditions, by maintaining the basal VEGFR phosphorylation to a minimal level.

In contrast to PTP1B, inhibition of PTEN, another key regulator of Akt activation, was found to have no significant effects on the prosurvival effects of Nox4 overexpression. Although PTEN is also sensitive to ROS-induced inactivation, our results suggest that Nox4 overexpression-induced actions were unlikely to be related to changes in PTEN functions. It is surprising that inhibition of PTEN did not significantly alter the Akt phosphorylation level under our experimental conditions; and we are not clear whether this is related to the relative basal expression level of PTEN in cultured endothelial cells.

Another important finding in our study was that treatment with TGF- $\beta$ significantly increased the expression of the arterial marker EphrinB2, and enhanced Notch signaling (increased expression of Notch receptors and ligands, increased nuclear accumulation of NICD and upregulation of Notch target genes), suggesting that TGF- $\beta$ participated in promoting arterial specification of endothelial cells. ${ }^{26,27}$ In contrast, TGF- $\beta$ had little effect on the venous marker EphB4. Moreover, we showed that these effects of TGF- $\beta$ were redox dependent, as pre-treatment with antioxidant diminished the TGF- $\beta$ effects, whereas exogenous $\mathrm{H}_{2} \mathrm{O}_{2}$ mimicked the effects. To our knowledge, this is the first report that regulation of arterial-venous specification is also sensitive to redox control. Notch signaling has a central role in inducing and maintaining the arterial phenotype of endothelial cells. ${ }^{26,27}$ Coant et al. ${ }^{50}$ demonstrated that in mouse colon, Nox1 NADPH oxidase deficiency resulted in depletion of progenitor cells, which was accompanied by concomitant repression of Notch1 signaling. In addition, it was shown that in vascular smooth muscle cells, mechanical 

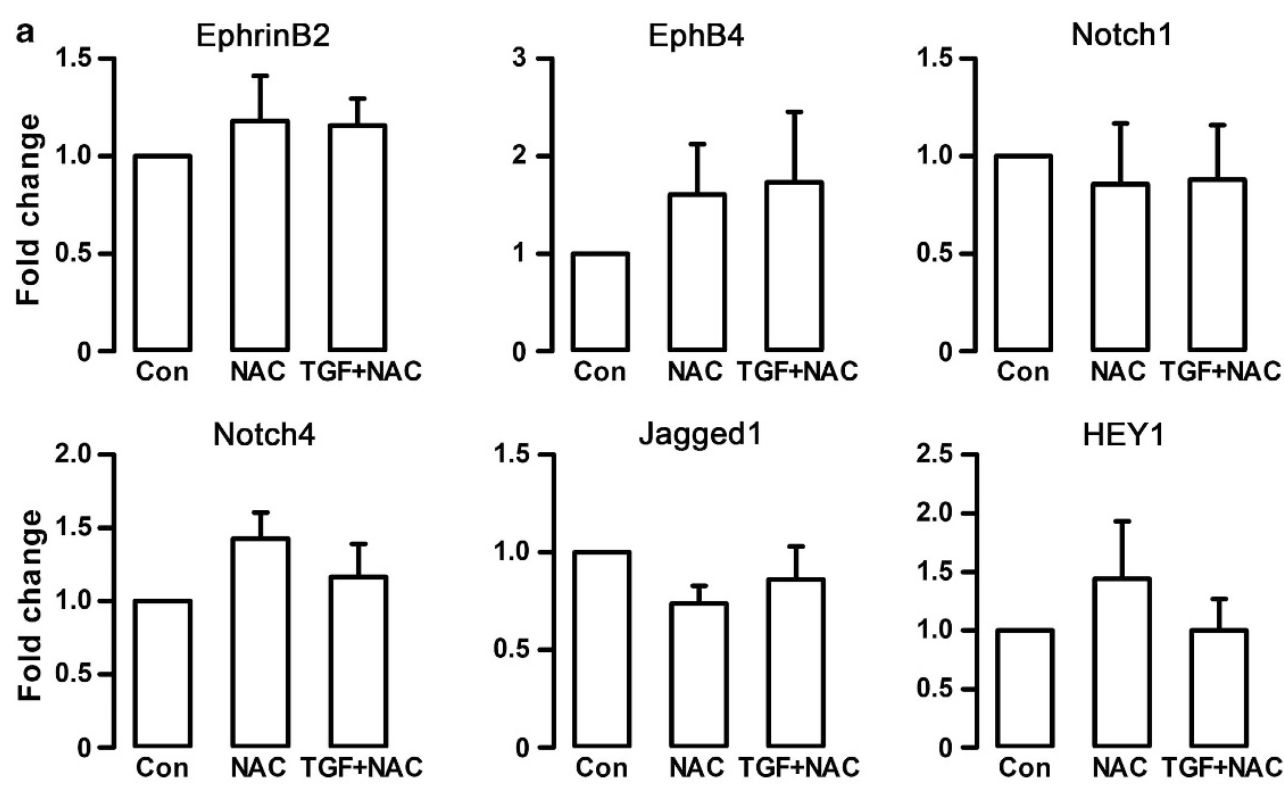

b

EphrinB2

EphB4

Notch1
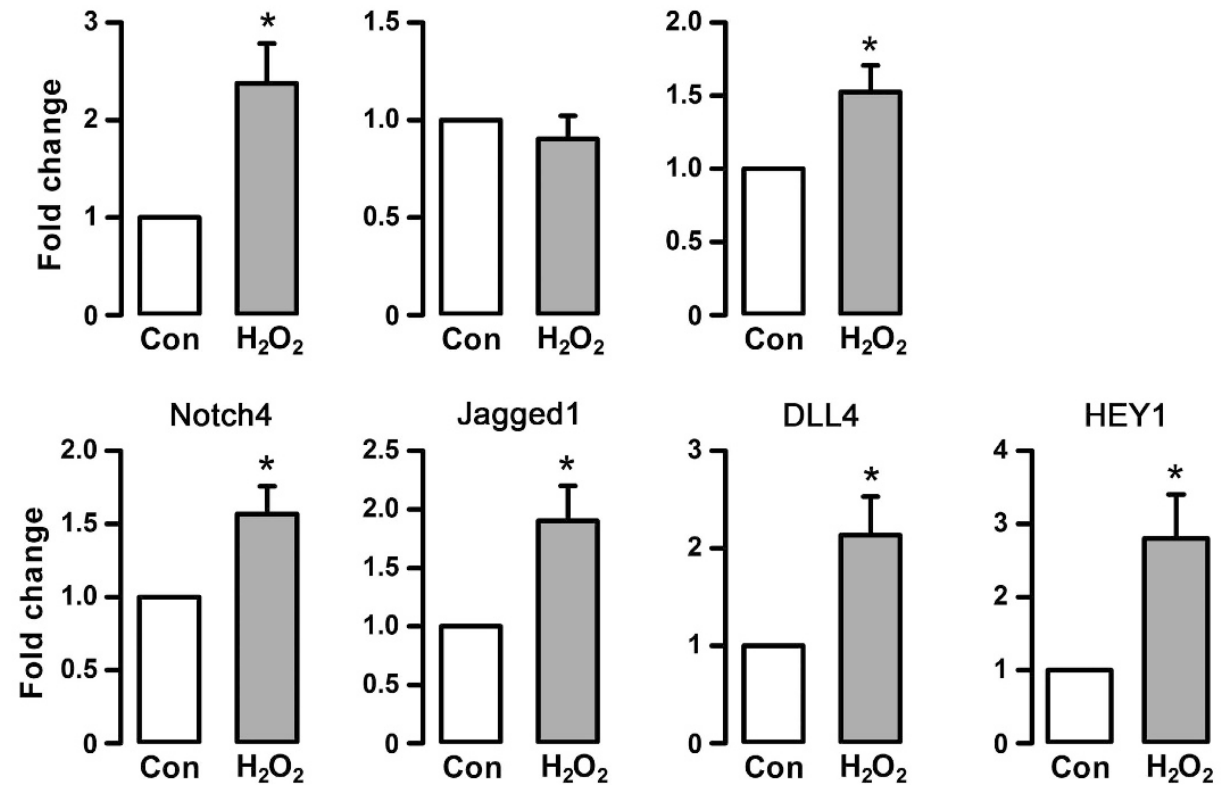

Figure 8 (a) The stimulating effects of TGF- $\beta$ on arterial markers were diminished in the presence of NAC. Gene expression was measured with qPCR. (b) Effects of exogenous application of $\mathrm{H}_{2} \mathrm{O}_{2}(100 \mu \mathrm{M}$ for $24 \mathrm{~h})$ on expression of arterial-venous markers in HUVECs measured with qPCR. Data are mean $\pm \mathrm{S}$.E.M. ${ }^{*} P<0.05$ versus control, unpaired $t$-test $(n=4-5)$

cyclic stretch could induce activation of the Notch3 pathway in a redox-dependent manner. ${ }^{51}$ Moreover, our results were further supported by one of our previous studies in rats, showing that the newly formed blood vessels during angiogenesis had smaller (malformed) lumens after inhibition of NADPH oxidase activity in vivo, whereas the total number of new vessels per unit area was not changed. ${ }^{52}$ Interestingly, this kind of effect of NADPH oxidase inhibition in angiogenic blood vessel development was reminiscent of those reported in a tumor angiogenesis model in Notch1-deficient mice. ${ }^{53}$ Taken together, we suggest that redox-dependent mechanisms may have significant impacts on arterial-venous specification during blood vessel development or regeneration by modulating Notch signaling. However, a limitation of this study was that the experiments were performed in differentiated endothelial cells but not in stem cells or progenitor cells. Nevertheless, we showed that the arterial markers were not changed by TGF- $\beta$ in microvascular endothelial cells, indicating that the observed effects of TGF- $\beta$ on arterial marker expression in HUVEC were not a nonspecific action. We cannot exclude the possibility that the lack of effect with TGF- $\beta$ in microvascular endothelial cells is due to that microvascular endothelial cells have gained a relatively arterial phenotype in culture. 
EphrinB2
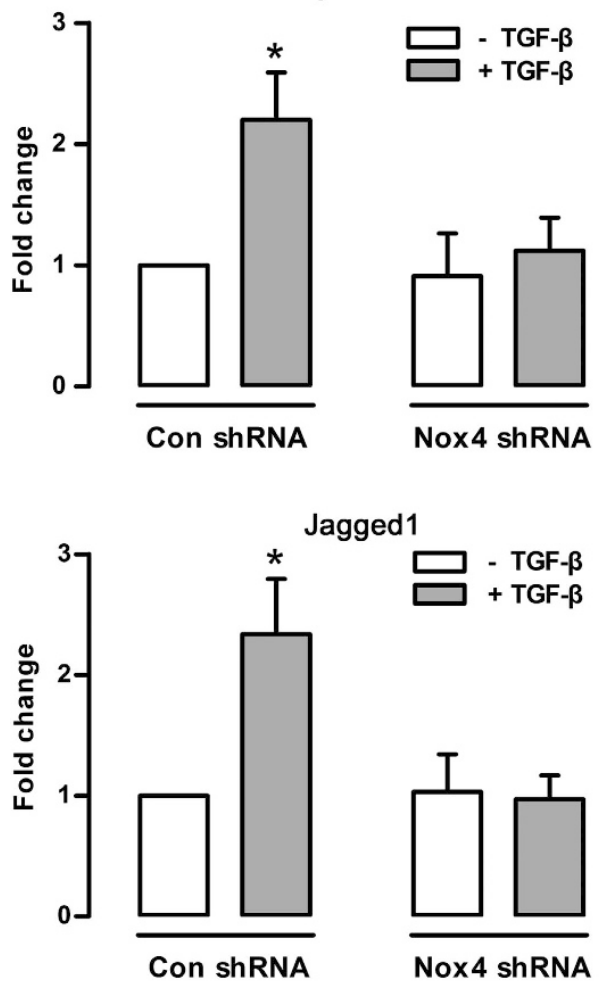
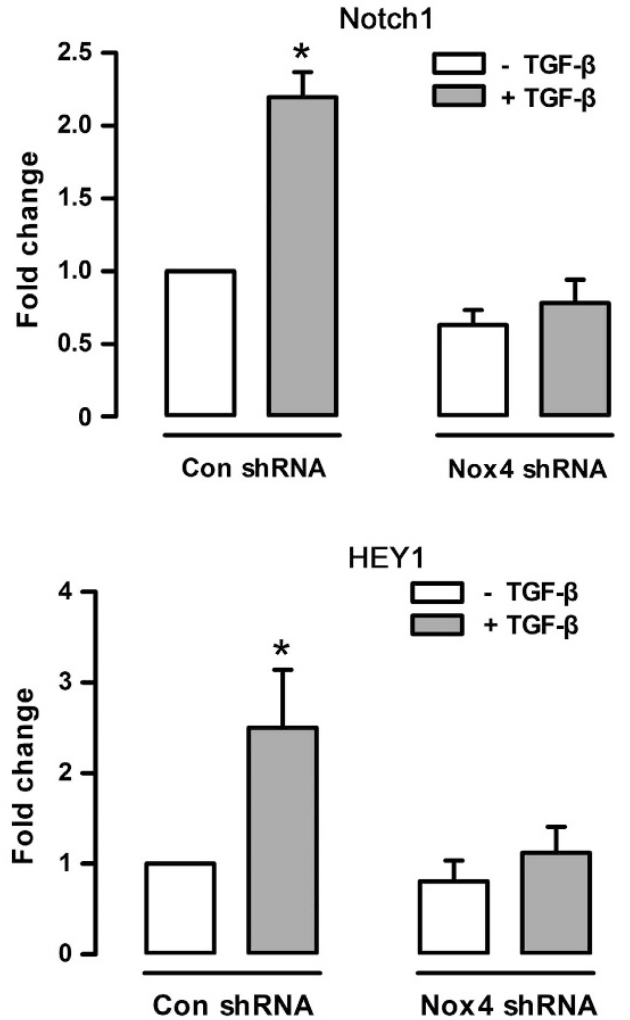

Figure 9 TGF- $\beta$-induced arterial marker expression was diminished by Nox4 gene silencing. HUVECs were incubated with lentiviruses expressing control or Nox4 shRNA and stimulated with TGF- $\beta$ of $1 \mathrm{ng} / \mathrm{ml}$ for $24 \mathrm{~h}$. Data are mean \pm S.E.M. ${ }^{*} P<0.05$ versus control, one-way ANOVA $(n=4)$

In summary, we have provided evidence suggesting that Nox4 and ROS have pivotal roles in mediating TGF- $\beta$-induced endothelial apoptosis and phenotype specification. Redox mechanisms may influence endothelial cell functions by modulating p38, PTP1B/VEGFR/Akt and Notch signaling pathways. We suggest that our results have opened a new avenue for exploring novel redox-sensitive signaling mechanisms involved in determination of the arterial-venous specification of endothelial cells.

\section{Materials and Methods}

Reagents. Recombinant human TGF- $\beta 1$ was purchased from Invitrogen (Carlsbad, CA, USA). Recombinant human VEGF165 was purchased from R\&D Systems (Minneapolis, MN, USA). Primary antibodies against cleaved caspase3, caspase3, VEGFR2, phospho-tyrosine, phosphorylated and total p38, JNK, ERK1/2 and Akt were purchased from Cell Signaling Technology (Beverley, MA, USA). Polyclonal antibodies for Ephrin B2 and DLL4 were purchased from Thermo Scientific (Rockford, IL, USA). Anti-NICD antibody was purchased from Abcam (Cambridge, UK). Staurosporine, SB431542 (ALK5 inhibitor), VAS2870 (Nox inhibitor), JNK Inhibitor II, SB202190 (p38 inhibitor), wortmannin (PI3 kinase inhibitor), bpV(phen) (PTEN Inhibitor), PTP1B inhibitor, U0126 (ERK pathway inhibitor) and NAC were all from Merck Millipore (Darmstadt, Germany). Akt Inhibitor VIII, DTT and $\mathrm{H}_{2} \mathrm{O}_{2}$ were from Sigma (St. Louis, MO, USA). EUK-134 was purchased from Cayman Chemicals (Ann Arbor, MI, USA).

Cell culture. HUVECs and immortalized HMVECs were purchased from the American Type Culture Collection (ATCC, Rockville, MD, USA). Cells were cultured in complete endothelial cell medium (ECM; ScienCell, Carlsbad, CA, USA) containing $5 \%$ fetal bovine serum in a humidified incubator with $5 \% \mathrm{CO}_{2}$ at $37^{\circ} \mathrm{C}$. HUVECs used for the experiments were between passages 3 and 6 .
Viral vectors. For RNA interference experiments, we routinely screened three different shRNA constructs for each gene and chose the one with highest efficacy. Lentiviral vectors carrying a shRNA targeting human Nox4 were purchased from GenePharma (Shanghai, China). The targeting sequence for Nox4 was $5^{\prime}$-GCTGT ATATTGATGGTCCTTT-3'. A scrambled sequence of $5^{\prime}$-GGTGTCTTCGAATTTAT GTCT-3' was used as control. A cDNA clone of human wild-type Nox4 was purchased from Origene (Rockville, MD, USA) and subcloned into pLV.EX3d.P/ neo-EF1A (Cyagen Biosciences, Guangzhou, China). Lentiviruses expressing human Nox4 or GFP (control) were produced in 293FT cells and concentrated by ultracentrifugation. For cell transfection, HUVECs were seeded in 24-well plates at 50000 cells per well in $0.5 \mathrm{ml}$ ECM. Viral stocks were diluted in ECM containing $5 \mu \mathrm{g} / \mathrm{ml}$ of polybrene and added to the cells at different multiplicities of infection. Medium were changed $12-24 \mathrm{~h}$ after, and experiments were performed $48 \mathrm{~h}$ after transfection. Adenoviruses expressing wild-type human Nox4 (a gift from Dr. Goldstein, Jefferson Medical College of Thomas Jefferson University, Philadelphia, PA, USA) were used as described previously. ${ }^{24}$

ROS measurement. Intracellular ROS was measured with DCFH-DA (Life Technologies, Carlsbad, CA, USA) fluorescence. Cells were incubated with $5 \mu \mathrm{M}$ DCFH-DA at $37^{\circ} \mathrm{C}$ for 20 min in Hanks' balanced salt solution. After staining, cells were rinsed with saline and recovered in complete ECM and immediately detected with a laser-scanning confocal microscope (Model LSM710, Zeiss, Jena, Germany). The fluorescent intensity was measured with Image-Pro Plus software (Media Cybernetics, Atlanta, GA, USA). In separate experiments, DCFH-DA fluorescence was quantified by transferring cells to a 96-well white-walled plate and detecting the fluorescent signal with a Varioskan Flash plate reader (Thermo Scientific).

Measurement of $\Delta \Psi \mathbf{m}$. The fluorescent probe JC-1 (Life Technologies) was used to determine changes in $\Delta \Psi \mathrm{m}$. Cells were stained with $\mathrm{JC}-1$ at $37^{\circ} \mathrm{C}$ for $20 \mathrm{~min}$ and analyzed by either flow cytometry (FACSCalibur, BD, Franklin Lakes, $\mathrm{NJ}, \mathrm{USA}$ ) or confocal microscopy. Decreased $\Delta \Psi \mathrm{m}$ is reflected by the decrease in red fluorescence (dye accumulated in mitochondria). 
Real-time PCR. Total RNA was extracted with TRIzol reagent (Invitrogen) and RNA concentrations determined by NanoDrop ND-1000 spectrophotometer (Nanodrop Technologies, Wilmington, DE, USA). The first-strand CDNA was synthesized from $1 \mu \mathrm{g}$ total RNA using random primers and the TaqMan reverse transcription reagents (Applied Biosystems, Foster City, CA, USA). Real-time PCR was performed using predesigned Taqman probe-primer sets and the Gene Expression Master Mix (Applied Biosystems) in a Prism 7500 system (Applied Biosystems), except for DLL4, which was measured with the SYBR Green method using SsoFas EvaGreen Supermix (Bio-Rad, Hercules, CA, USA). Primers for DLL4 were: sense $5^{\prime}$-GGTCAGAACTGGTTATTGGAT-3'; antisense 5'-CCCGAAA GACAGATAGGCT-3'. GAPDH or $18 \mathrm{~S}$ was used as house-keeping gene. The $2^{-\Delta \Delta C t}$ method was used to assess the relative mRNA expression level.

Immunoprecipitation and western blot. Cells were homogenized in cold lysis buffer ( $50 \mathrm{mM}$ Tris, pH 7.5, $2 \mathrm{mM}$ EDTA, $100 \mathrm{mM} \mathrm{NaCl}, 50 \mathrm{mM} \mathrm{NaF}, 1 \%$ Triton X-100, $1 \mathrm{mM} \mathrm{Na}_{3} \mathrm{VO}_{4}$ and $40 \mathrm{mM} \quad \beta$-glycerol phosphate) with added protease inhibitor cocktail (Roche, Mannheim, Germany). For immunoprecipitation, cell lysates were precleared and incubated with $2 \mu \mathrm{g}$ of antibody and $20 \mu \mathrm{l}$ of $50 \%$ protein A or G agarose bead slurry (Pierce Biotechnology, Rockford, IL, USA) overnight at $4{ }^{\circ} \mathrm{C}$ with gentle rotation. The beads were washed and boiled in $3 \times$ Laemmli sample buffer. For western blot, protein samples were separated by SDS-PAGE and electro-transferred to nitrocellulose membranes. The membrane was blocked with $5 \%$ nonfat milk and incubated with specific primary antibodies overnight. Secondary HRP-conjugated antibodies were developed with ECL Prime reagents (GE, Piscataway, NJ, USA) and detected with a LAS-4000 luminescent image analyzer (Fujifilm, Stamford, CT, USA). The densitometry analysis was performed with Image-J software (NIH, Bethesda, MA, USA).

Immunofluorescence. Cells cultured on Lab-Tek chamber slides were fixed in $4 \%$ paraformaldehyde and rinsed in PBS. Cells were incubated with diluted primary antibodies overnight and then with Alexa Fluor 594-conjugated secondary antibodies (Jackson ImmunoResearch Laboratories, West Grove, PA, USA) at room temperature for $2 \mathrm{~h}$, and counter stained with DAPI for $15 \mathrm{~min}$. Stained cells were photographed using a confocal microscope.

TUNEL labeling. TUNEL was performed using ApopTag Plus Peroxidase In Situ Apoptosis Detection Kit (Merck Millipore) following the manufacturer's protocol. The number of TUNEL-positive cells were counted and averaged across 10 random fields from four independent experiments each.

Caspase3/7 activity assay. Cells seeded in 96-well plates were incubated with the Caspase-Glo $3 / 7$ substrate reagent (Promega, Madison, WI, USA) at $37^{\circ} \mathrm{C}$ for $30 \mathrm{~min}$. The samples were transferred to a white-walled plate and the luminescence signal was measured in a Varioskan Flash plate reader (Thermo Scientific).

PTP1B activity assay. PTP1B activity was measured in immunoprecipitated PTP1B protein samples using a PTP colorimetric assay kit from Millipore (Temecula, CA, USA) according to the manufacturer's instruction.

Transfection with siRNA. Three sequences of siRNA targeting p38 $\alpha$ and JNK1 each were purchased from GenePharma and transfected into HUVECs using Lipofectamine RNAiMAX Reagent (Life Technologies) according to the manufacturer's protocol. Gene silencing efficiency was determined by western blot. Further experiments were carried out $48 \mathrm{~h}$ after transfection.

Statistical analysis. Data are presented as mean \pm S.E.M. Data analysis was performed with unpaired $t$-test or one-way analysis of variance followed by post hoc Newman-Keuls test as appropriate. $P<0.05$ was considered as statistically significant.

\section{Conflict of Interest}

The authors declare no conflict of interest.

Acknowledgements. We thank Fang-Fang Liu and Yong-Tao Zhang for technical assistances. This work was partially supported by the following research grants: National 973 Basic Research Program of China (2010CB732605 for FJ, 2011 CB503906 for MZ); National Natural Science Foundation of China (81070164 for FJ).
1. Goumans MJ, Liu Z, ten Dijke P. TGF-beta signaling in vascular biology and dysfunction. Cell Res 2009; 19: 116-127.

2. Jakobsson L, van Meeteren LA. Transforming growth factor beta family members in regulation of vascular function: in the light of vascular conditional knockouts. Exp Cell Res 2013; 319: 1264-1270.

3. Pardali E, Goumans MJ, ten Dijke P. Signaling by members of the TGF-beta family in vascular morphogenesis and disease. Trends Cell Biol 2010; 20: 556-567.

4. Roberts $A B$, Sporn MB. Regulation of endothelial cell growth, architecture, and matrix synthesis by TGF-beta. Am Rev Respir Dis 1989; 140: 1126-1128.

5. Myoken Y, Kan M, Sato GH, McKeehan WL, Sato JD. Bifunctional effects of transforming growth factor-beta (TGF-beta) on endothelial cell growth correlate with phenotypes of TGF-beta binding sites. Exp Cell Res 1990; 191: 299-304.

6. Lee YH, Kayyali US, Sousa AM, Rajan T, Lechleider RJ, Day RM. Transforming growth factor-beta1 effects on endothelial monolayer permeability involve focal adhesion kinase/ Src. Am J Respir Cell Mol Biol 2007; 37: 485-493.

7. Lu Q, Patel B, Harrington EO, Rounds S. Transforming growth factor-beta1 causes pulmonary microvascular endothelial cell apoptosis via ALK5. Am J Physiol Lung Cell Mol Physiol 2009; 296: L825-L838

8. Pfeiffer A, Middelberg-Bisping K, Drewes C, Schatz H. Elevated plasma levels of transforming growth factor-beta 1 in NIDDM. Diabetes Care 1996; 19: 1113-1117.

9. Scaglione R, Argano C, di Chiara T, Colomba D, Parrinello G, Corrao S et al. Central obesity and hypertensive renal disease: association between higher levels of BMI, circulating transforming growth factor beta1 and urinary albumin excretion. Blood Press 2003; 12: 269-276.

10. Djurovic S, Schjetlein R, Wisloff F, Haugen G, Husby H, Berg K. Plasma concentrations of Lp(a) lipoprotein and TGF-beta1 are altered in preeclampsia. Clin Genet 1997; 52: 371-376.

11. Buday A, Orsy P, Godo M, Mozes M, Kokeny G, Lacza Z et al. Elevated systemic TGF-beta impairs aortic vasomotor function through activation of NADPH oxidase-driven superoxide production and leads to hypertension, myocardial remodeling, and increased plaque formation in apoE(--/) mice. Am J Physiol Heart Circ Physiol 2010; 299: H386-H395.

12. Iruela-Arispe ML, Sage EH. Endothelial cells exhibiting angiogenesis in vitro proliferate in response to TGF-beta 1. J Cell Biochem 1993; 52: 414-430.

13. Lu Q. Transforming growth factor-beta1 protects against pulmonary artery endothelial cell apoptosis via ALK5. Am J Physiol Lung Cell Mol Physiol 2008; 295: L123-L133.

14. Orlova VV, Liu Z, Goumans MJ, ten Dijke P. Controlling angiogenesis by two unique TGF-beta type I receptor signaling pathways. Histol Histopathol 2011; 26: 1219-1230.

15. Sturrock A, Cahill B, Norman K, Huecksteadt TP, Hill K, Sanders K et al. Transforming growth factor-beta1 induces Nox4 NAD(P)H oxidase and reactive oxygen speciesdependent proliferation in human pulmonary artery smooth muscle cells. Am J Physiol Lung Cell Mol Physiol 2006; 290: L661-L673.

16. Cucoranu I, Clempus R, Dikalova A, Phelan PJ, Ariyan S, Dikalov S et al. NAD(P)H oxidase 4 mediates transforming growth factor-beta1-induced differentiation of cardiac fibroblasts into myofibroblasts. Circ Res 2005; 97: 900-907.

17. Carmona-Cuenca I, Roncero C, Sancho P, Caja L, Fausto N, Fernandez M et al. Upregulation of the NADPH oxidase NOX4 by TGF-beta in hepatocytes is required for its pro-apoptotic activity. J Hepatol 2008; 49: 965-976.

18. Amara N, Goven D, Prost F, Muloway R, Crestani B, Boczkowski J. NOX4/NADPH oxidase expression is increased in pulmonary fibroblasts from patients with idiopathic pulmonary fibrosis and mediates TGFbeta1-induced fibroblast differentiation into myofibroblasts. Thorax 2010; 65: 733-738.

19. Boudreau HE, Casterline BW, Rada B, Korzeniowska A, Leto TL. Nox4 involvement in TGF-beta and SMAD3-driven induction of the epithelial-to-mesenchymal transition and migration of breast epithelial cells. Free Radic Biol Med 2012; 53: 1489-1499.

20. Pollman MJ, Naumovski L, Gibbons GH. Vascular cell apoptosis: cell type-specific modulation by transforming growth factor-beta1 in endothelial cells versus smooth muscle cells. Circulation 1999; 99: 2019-2026.

21. Hyman KM, Seghezzi G, Pintucci G, Stellari G, Kim JH, Grossi EA et al. Transforming growth factor-beta1 induces apoptosis in vascular endothelial cells by activation of mitogen-activated protein kinase. Surgery 2002; 132: 173-179.

22. Ferrari G, Pintucci G, Seghezzi G, Hyman K, Galloway AC, Mignatti P. VEGF, a prosurvival factor, acts in concert with TGF-beta1 to induce endothelial cell apoptosis. Proc Natl Acad Sci USA 2006; 103: 17260-17265.

23. Carnesecchi S, Deffert C, Donati Y, Basset O, Hinz B, Preynat-Seauve $O$ et al. A key role for NOX4 in epithelial cell death during development of lung fibrosis. Antioxid Redox Signal 2011; 15: 607-619.

24. Datla SR, Peshavariya H, Dusting GJ, Mahadev K, Goldstein BJ, Jiang F. Important role of Nox4 type NADPH oxidase in angiogenic responses in human microvascular endothelial cells in vitro. Arterioscler Thromb Vasc Biol 2007; 27: 2319-2324.

25. Peshavariya H, Dusting GJ, Jiang F, Halmos LR, Sobey CG, Drummond GR et al. NADPH oxidase isoform selective regulation of endothelial cell proliferation and survival. Naunyn Schmiedebergs Arch Pharmacol 2009; 380: 193-204.

26. Swift MR, Weinstein BM. Arterial-venous specification during development. Circ Res 2009; 104: $576-588$.

27. Harvey NL, Oliver G. Choose your fate: artery, vein or lymphatic vessel? Curr Opin Genet Dev 2004; 14: 499-505. 
28. Park SO, Lee YJ, Seki T, Hong KH, Fliess N, Jiang Z et al. ALK5- and TGFBR2independent role of ALK1 in the pathogenesis of hereditary hemorrhagic telangiectasia type 2. Blood 2008; 111: 633-642.

29. Mahmoud M, Allinson KR, Zhai Z, Oakenfull R, Ghandi P, Adams RH et al. Pathogenesis of arteriovenous malformations in the absence of endoglin. Circ Res 2010; 106: 1425-1433.

30. Hirashima M, Suda T. Differentiation of arterial and venous endothelial cells and vascular morphogenesis. Endothelium 2006; 13: 137-145.

31. Sardina JL, Lopez-Ruano G, Sanchez-Sanchez B, Llanillo M, Hernandez-Hernandez A. Reactive oxygen species: are they important for haematopoiesis? Crit Rev Oncol Hematol 2012; 81: 257-274

32. Liu GS, Chan EC, Higuchi M, Dusting GJ, Jiang F. Redox mechanisms in regulation of adipocyte differentiation: beyond a general stress response. Cells 2012; 1: 976-993.

33. Vieira HL, Alves PM, Vercelli A. Modulation of neuronal stem cell differentiation by hypoxia and reactive oxygen species. Prog Neurobiol 2011; 93: 444-455.

34. Jiang F, Zhang Y, Dusting GJ. NADPH oxidase-mediated redox signaling: roles in cellular stress response, stress tolerance, and tissue repair. Pharmacol Rev 2011; 63: 218-242.

35. Ago $\mathrm{T}$, Kitazono $\mathrm{T}$, Ooboshi $\mathrm{H}$, lyama $\mathrm{T}$, Han $\mathrm{YH}$, Takada $\mathrm{J}$ et al. Nox4 as the major catalytic component of an endothelial NAD(P)H oxidase. Circulation 2004; 109: 227-233.

36. Jiang F, Roberts SJ, Datla Sr, Dusting GJ. NO modulates NADPH oxidase function via heme oxygenase-1 in human endothelial cells. Hypertension 2006; 48: 950-957.

37. Sancho P, Mainez J, Crosas-Molist E, Roncero C, Fernandez-Rodriguez CM, Pinedo F et al. NADPH oxidase NOX4 mediates stellate cell activation and hepatocyte cell death during liver fibrosis development. PLOS One 2012; 7: e45285.

38. Hecker L, Vittal R, Jones T, Jagirdar R, Luckhardt TR, Horowitz JC et al. NADPH oxidase-4 mediates myofibroblast activation and fibrogenic responses to lung injury. Nat Med 2009; 15: 1077-1081.

39. Circu ML, Aw TY. Reactive oxygen species, cellular redox systems, and apoptosis. Free Radic Biol Med 2010; 48: 749-762.

40. Liao JH, Chen JS, Chai MQ, Zhao S, Song JG. The involvement of p38 MAPK in transforming growth factor beta1-induced apoptosis in murine hepatocytes. Cell Res 2001; 11: 89-94.

41. Edlund S, Bu S, Schuster N, Aspenstrom P, Heuchel R, Heldin NE et al. Transforming growth factor-beta1 (TGF-beta)-induced apoptosis of prostate cancer cells involves Smad7-dependent activation of $\mathrm{p} 38$ by TGF-beta-activated kinase 1 and mitogen-activated protein kinase kinase 3. Mol Biol Cell 2003; 14: 529-544.

42. Cai B, Chang SH, Becker EB, Bonni A, Xia Z. p38 MAP kinase mediates apoptosis through phosphorylation of BimEL at Ser-65. J Biol Chem 2006; 281: 25215-25222.

43. Kim BJ, Ryu SW, Song BJ. JNK- and p38 kinase-mediated phosphorylation of Bax leads to its activation and mitochondrial translocation and to apoptosis of human hepatoma HepG2 cells. J Biol Chem 2006; 281: 21256-21265.
44. Goettsch C, Goettsch W, Muller G, Seebach J, Schnittler HJ, Morawietz H. Nox4 overexpression activates reactive oxygen species and p38 MAPK in human endothelial cells. Biochem Biophys Res Commun 2009; 380: 355-360.

45. Van Laethem A, Nys K, Van Kelst S, Claerhout S, Ichijo H, Vandenheede JR et al. Apoptosis signal regulating kinase-1 connects reactive oxygen species to p38 MAPKinduced mitochondrial apoptosis in UVB-irradiated human keratinocytes. Free Radic Biol Med 2006; 41: 1361-1371.

46. Noguchi T, Ishii K, Fukutomi H, Naguro I, Matsuzawa A, Takeda K et al. Requirement of reactive oxygen species-dependent activation of ASK1-p38 MAPK pathway for extracellular ATP-induced apoptosis in macrophage. J Biol Chem 2008; 283: 7657-7665.

47. Xu H, Goettsch C, Xia N, Horke S, Morawietz H, Forstermann U et al. Differential roles of PKCalpha and PKCepsilon in controlling the gene expression of Nox4 in human endothelial cells. Free Radic Biol Med 2008; 44: 1656-1667.

48. Haurani MJ, Cifuentes ME, Shepard AD, Pagano PJ. Nox4 oxidase overexpression specifically decreases endogenous Nox4 mRNA and inhibits angiotensin II-induced adventitial myofibroblast migration. Hypertension 2008; 52: 143-149.

49. Nakamura Y, Patrushev N, Inomata H, Mehta D, Urao N, Kim HW et al. Role of protein tyrosine phosphatase $1 \mathrm{~B}$ in vascular endothelial growth factor signaling and cell-cell adhesions in endothelial cells. Circ Res 2008; 102: 1182-1191.

50. Coant N, Ben Mkaddem S, Pedruzzi E, Guichard C, Treton X, Ducroc R et al. NADPH oxidase 1 modulates WNT and NOTCH1 signaling to control the fate of proliferative progenitor cells in the colon. Mol Cell Biol 2010; 30: 2636-2650.

51. Zhu JH, Chen CL, Flavahan S, Harr J, Su B, Flavahan NA. Cyclic stretch stimulates vascular smooth muscle cell alignment by redox-dependent activation of Notch3. Am J Physiol Heart Circ Physiol 2011; 300: H1770-H1780.

52. Hachisuka H, Dusting GJ, Abberton KM, Morrison WA, Jiang F. Role of NADPH oxidase in tissue growth in a tissue engineering chamber in rats. J Tissue Eng Regen Med 2008; 2: 430-435.

53. Hellstrom M, Phng LK, Hofmann JJ, Wallgard E, Coultas L, Lindblom P et al. DIl4 signalling through Notch1 regulates formation of tip cells during angiogenesis. Nature 2007; 445: 776-780.

(c) (i) (2) $\odot$ Cell Death and Disease is an open-access journal cc) published by Nature Publishing Group. This work is licensed under a Creative Commons Attribution-NonCommercialNoDerivs 3.0 Unported License. To view a copy of this license, visit http://creativecommons.org/licenses/by-nc-nd/3.0/

\section{Supplementary Information accompanies this paper on Cell Death and Disease website (http://www.nature.com/cddis)}

